\title{
TU/e EmonONEN

\section{A theoretical method for calculating the collapse load of steel circular arches}

Citation for published version (APA):

Spoorenberg, R. C., Snijder, H. H., \& Hoenderkamp, J. C. D. (2012). A theoretical method for calculating the collapse load of steel circular arches. Engineering Structures, 38, 89-103.

https://doi.org/10.1016/j.engstruct.2011.12.047

DOI:

10.1016/j.engstruct.2011.12.047

Document status and date:

Published: 01/01/2012

Document Version:

Accepted manuscript including changes made at the peer-review stage

Please check the document version of this publication:

- A submitted manuscript is the version of the article upon submission and before peer-review. There can be important differences between the submitted version and the official published version of record. People interested in the research are advised to contact the author for the final version of the publication, or visit the $\mathrm{DOI}$ to the publisher's website.

- The final author version and the galley proof are versions of the publication after peer review.

- The final published version features the final layout of the paper including the volume, issue and page numbers.

Link to publication

\section{General rights}

Copyright and moral rights for the publications made accessible in the public portal are retained by the authors and/or other copyright owners and it is a condition of accessing publications that users recognise and abide by the legal requirements associated with these rights.

- Users may download and print one copy of any publication from the public portal for the purpose of private study or research.

- You may not further distribute the material or use it for any profit-making activity or commercial gain

- You may freely distribute the URL identifying the publication in the public portal.

If the publication is distributed under the terms of Article 25fa of the Dutch Copyright Act, indicated by the "Taverne" license above, please follow below link for the End User Agreement:

www.tue.nl/taverne

Take down policy

If you believe that this document breaches copyright please contact us at:

openaccess@tue.nl

providing details and we will investigate your claim. 
Provided for non-commercial research and education use. Not for reproduction, distribution or commercial use.

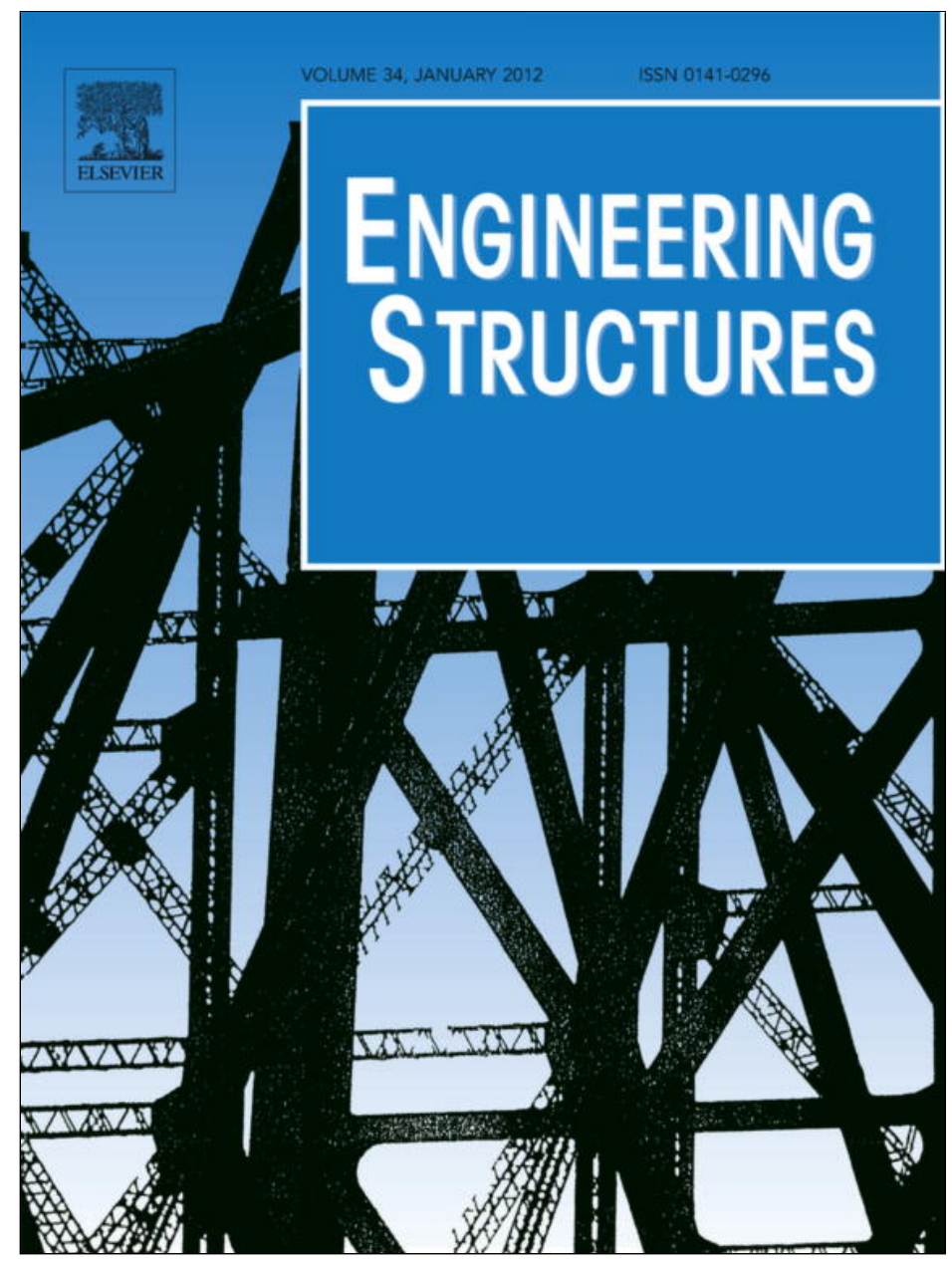

(This is a sample cover image for this issue. The actual cover is not yet available at this time.)

This article appeared in a journal published by Elsevier. The attached copy is furnished to the author for internal non-commercial research and education use, including for instruction at the authors institution and sharing with colleagues.

Other uses, including reproduction and distribution, or selling or licensing copies, or posting to personal, institutional or third party websites are prohibited.

In most cases authors are permitted to post their version of the article (e.g. in Word or Tex form) to their personal website or institutional repository. Authors requiring further information regarding Elsevier's archiving and manuscript policies are encouraged to visit:

http://www.elsevier.com/copyright 


\title{
A theoretical method for calculating the collapse load of steel circular arches
}

\author{
R.C. Spoorenberg *, H.H. Snijder, J.C.D. Hoenderkamp \\ Eindhoven University of Technology, Faculty of Architecture, Building and Planning, P.O. Box 513, 5600 MB Eindhoven, The Netherlands
}

\section{A R T I C L E I N F O}

\section{Article history:}

Received 31 October 2011

Revised 20 December 2011

Accepted 22 December 2011

\section{Keywords:}

Steel circular arch

Plastic collapse load

Yield contour

Kinematic admissibility

Iterative method

\begin{abstract}
A B S T R A C T
Arches are frequently used in large span structures like bridges and roofs. Although these structural elements may be prone to various instability phenomena, stocky arches or slender arches with sufficient lateral bracing fail due to plastic collapse instead of in-plane buckling or out-of-plane buckling. The plastic collapse load can be obtained through limit load analyses, making full use of the plastic capacity of the cross-section and possible redistribution of internal forces after formation of the first hinge. This paper describes an analytical approach to obtain the plastic collapse load of circular steel arches subjected to vertical loading. The upper-bound theorem, lower-bound theorem and kinematic admissibility rules of plastic theory were employed to arrive at a plastic collapse load. Reduction of the full plastic moment capacity of the arch cross-section due to the presence of compressive forces was accounted for. An iterative procedure was found necessary to obtain the plastic collapse load since a non-linear relationship was observed between the acting loads and the reduced plastic moment capacity. Finite element analyses were performed to verify analytical results. Good agreement between the suggested iterative procedure and finite element computations was found. Design graphs were developed based on the iterative procedure.
\end{abstract}

(c) 2012 Elsevier Ltd. All rights reserved.

\section{Introduction}

Arches are frequently used in large-span roofs and bridges. The structural response of an arch is predominantly governed by the prevention of outward spreading of the supports, due to which the arch resists vertical loading by a combination of both bending and compressive internal forces. As most of the applied load is resisted by means of compressive forces instead of bending moments, arches can be designed with smaller sectional dimensions when compared to other structural shapes. The ratio between bending moments and compression forces in the arch-rib depends predominantly on the loading type and rise-to-span ratio of the arch. For instance: the maximum axial compression is larger in shallow arches than in deep arches. In addition, arches subjected to a central point load display larger bending moments than arches with a uniformly distributed load. With increased slenderness and lack of adequate bracing, arches are often susceptible to instability effects. Much has been reported on the structural stability behavior of steel arches and design rules have been proposed for both in-plane buckling (Fig. 1a) [1,2] and out-of-plane buckling (Fig. 1b) [3-5].

When sufficient bracing is provided, instability of an arch is no longer a decisive design criterion. In such cases the failure load is

\footnotetext{
* Corresponding author. Address: Eindhoven University of Technology, Faculty of Architecture, Building and Planning, Den Dolech 2, P.O. Box 513, $5600 \mathrm{MB}$ Eindhoven, The Netherlands. Tel.: +31 40247 2948; fax: +31 402450328.

E-mail address: r.c.spoorenberg@bwk.tue.nl (R.C. Spoorenberg).
}

governed by plastic collapse (Fig. 1c). Linear elastic analyses can be performed to obtain the load level at the onset of yielding, serving as a first estimate of the plastic collapse load. Although this method is very simple it does not take into account the plastic cross-section resistance nor does it account for possible redistribution of bending moments after formation of the first plastic hinge. This would yield conservative results.

\subsection{Previous investigations}

Analytical expressions to approximate the plastic collapse load were first suggested by Hendry [6]. The reduction of the full plastic moment capacity due to the presence of axial forces was not accounted for and the investigation was confined to parabolic arches. Onat and Prager [7] analyzed pin-supported circular arches subjected to a central point load or a uniformly distributed load over a half span or the full span and recognized the detrimental influence of the axial forces in the arch on the plastic collapse load. Circular and parabolic arches, either pin-supported or fixed were investigated by Stevens [8]. He proposed graphical methods to obtain the plastic collapse load. Cornforth and Childs [9] used an iterative technique to find the locations of the yield hinges in a statically indeterminate arch. The full plastic moments were not reduced by the presence of axial forces. Yamasaki and Ishikawa [10] used an analytical approach to investigate the plastic response of circular arches subjected to vertical loading. A kinematical approach was adopted by Maeda and Fujimoto [11] to investigate the plastic 


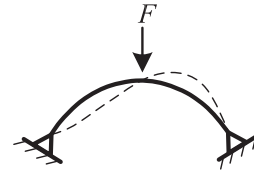

(a) In-plane instability

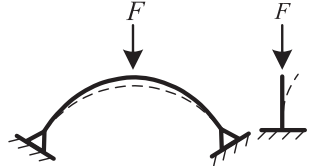

(b) Out-of-plane instability

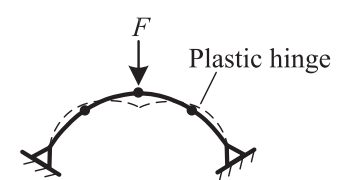

(c) In-plane plastic capacity

Fig. 1. Instability and plastic collapse load.

collapse load of parabolic and circular pin-supported arches. A piece-wise linearized yield contour was adopted and hinge locations were described by differential equations. The methodology was compared to full-scale experiments and moderate to good agreement was found. Design provisions were presented in graphical form, although limited to arches with a rectangular cross-section and a piece-wise linearized yield contour. Cohn and Abdel-Rohman [12] employed a computer method to analyze the elastic-plastic behavior of steel arches. The arch geometry was approximated by a series of straight elements. The influences of an approximated yield contour and taking into account the influences of with respect to the plastic collapse load were examined. The accuracy of the computer method was assessed by comparing results with theoretical work by Onat and Prager [7] and good agreement was found. Chakrabarty [13] presents design graphs for circular arches with a rectangular section subjected to a central point load. The design graphs are based on a lower bound and an upper bound approach. Both methodologies required the position on the yield contour for each yield hinge to be assumed beforehand and verified afterwards (i.e. the ratio between bending and axial force is estimated in advance). The in-plane collapse load of pin-supported circular arches with concentrated vertical loads was also investigated by Trahair et al. [14]. First-order plastic analyses were conducted with an in-house developed computer program which made part of a larger study on the structural behavior of steel arches. Closed form expressions to approximate the plastic collapse load were proposed for semicircular arches by La Poutre and Snijder [15] and later expanded to circular arches with various subtended angles, La Poutre [16]. An upper bound approach was employed based on the principle of virtual work. The influence of the normal force on the plastic capacity of the cross-section was not taken into account. The expressions showed close coherence with finite element results for semicircular arches but larger discrepancies were observed for arches with smaller subtended angles.

\subsection{Scope and aims}

The determination of the plastic collapse load of arch structures requires information about the cross-sectional properties, interaction between normal forces and bending moments, and yield hinge locations. Previous analyses have been confined to a single section type, most often rectangular sections or a single type of wide flange section using differential equations. The purpose of this investigation is to study the plastic collapse of circular arches consisting of steel wide flange sections, the influences of various geometrical factors on the plastic strength and to propose design graphs. The proposed analytical procedure is such that it allows easy change of structural parameters. The analytical results will be compared with finite element analyses and earlier studies. The scope of this study is confined to circular arches, with a constant cross-section, subjected to a central point load and a uniformly distributed vertical load along the horizontal projection. For arches with a central point load a further distinction is made between pin-supported arches and fixed supported arches (Fig. 2). The cross-sections are limited to steel wide flange sections bent about their major axis.

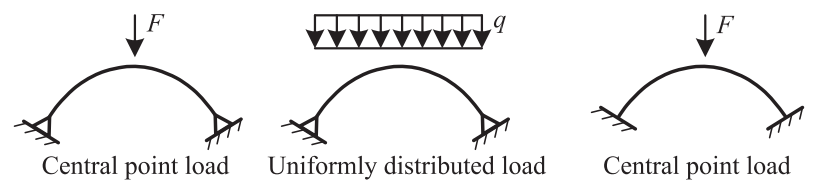

Fig. 2. Loadcases and support conditions under investigation.

The paper is confined to symmetrical loads only. Unsymmetrical loaded arches are more complex to analyze and are subject of future research.

Employing the analytical procedure to obtain plastic collapse loads for slender arches for which elastic-plastic buckling is the governing failure mode gives unconservative failure loads. However plastic collapse loads can be used as a reference value in view of elastic-plastic buckling analyses. Together with the elastic buckling load of an arch (closed-form equations are published in the structural stability guide by Ziemian [17]) the in-plane plastic collapse load is an arch parameter to describe capacity curves from which the elastic-plastic buckling load of the arch can be identified. This design procedure has already been adopted for shell structures in EN 1993 1-6 [18] but may similarly be applied to arches. This paper is confined to only the plastic collapse load of steel arches.

\section{Methodology for plastic collapse analysis}

To calculate plastic collapse loads, a lower-bound approach, an upper-bound approach or a combination can be used. In this investigation a lower-bound approach is employed and subsequently combined with the upper-bound theorem. First, a bending moment and normal force distribution is assumed that is in equilibrium with the external loads, without violating the yield criterion. Then the upper-bound theorem is applied by assuming a mechanism condition with a sufficient number of plastic hinges, depending on the loading and support conditions. An exact prediction of the collapse load is found when the bending moment distribution satisfies this mechanism condition. If the plastic moment capacity (reduced due to axial forces) is not exceeded anywhere, the collapse mechanism is found with the corresponding plastic collapse load. Finally the mode of deformation is checked to be in agreement with the kinematic admissibility of the collapse mode.

\subsection{Hinge locations}

A pin-supported arch has one degree of redundancy and so two plastic hinges must form before the arch can be reduced to a collapse mechanism (Fig. 3a). A fixed arch is indeterminate to the third degree and the formation of four hinges is required to obtain the plastic collapse load (Fig. 3b). Possible hinge locations are at the crown, at the supports and between the crown and supports. For symmetrical loading and support conditions the second hinge will appear simultaneously at two different locations on either side of the crown, rendering two hinges in excess of the degree of redundancy instead of one. The formation of three hinges or five 


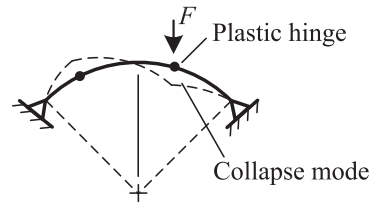

(a) 2 hinges in pin-supported arch

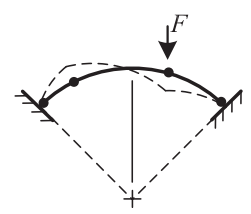

(b) 4 hinges in fixed arch

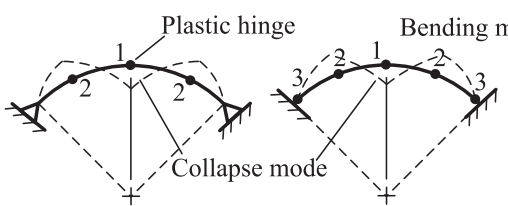

(c) 3 hinges in pinsupported arch (d) 5 hinges in fixed $\operatorname{arch}$

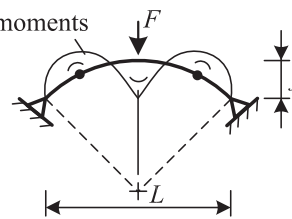

(e) Flexural mechanism for central point load

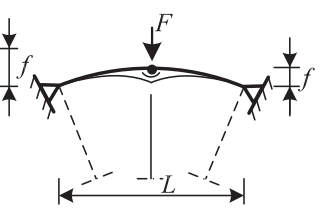

(f) Compressive mechanism for central point load

Fig. 3. Arch configuration, collapse mechanism and possible hinge locations.

hinges in a pin-supported arch or fixed arch respectively can take place provided that the arch is mostly under flexural action in which case it fails by a flexural mechanism (Fig. 3c and d). Most arches which have a considerable rise-to-span ratio $(f / L)$ fulfill this requirement, as the bending moments allow for the formation of a hinge between the crown and a support (Fig. 3e). However, this provision is jeopardized when the rise-to-span ratio of the arch decreases, in which case the arch is mostly in compression, see also Bakker et al. [19]. One hinge for a pin-supported arch and three hinges for a fixed arch can be sufficient to initiate a compressive mechanism (Fig. 3f). For shallow arches the assumption of a flexural mechanism may therefore yield inaccurate results. Stevens [8] reported that the rise-to-span ratio $(f / L)$ should be greater than 0.25 and the maximum axial force should not exceed $40 \%$ of the squash load of the cross-section in order to ensure that the arch is to a large extent subjected to bending. Whether a correct mechanism has been selected can be examined by checking the kinematic admissibility of the collapse mode.

Omitting the reduction of the full plastic moment would oversimplify the computations, since the use of a yield contour becomes obsolete and arch failure is governed by the full plastic moment capacity. In that situation plastic collapse loads will be overestimated. The extent of overestimation depends on the loads, support conditions and rise-to-span ratio of the arch [8]. Cohn and Abdel-Rohman [12] showed that by not taking into account the normal forces an overestimation of the collapse load by $53 \%$ is found for a pin-supported arch subjected to uniformly distributed loading.

\subsection{Assumptions}

The proposed analyses are based on the 1 st order plastic theory: equilibrium is defined with respect to the undeformed shape of the arch. The moment-curvature relationship of the cross-section is assumed to be of the rigid-plastic type (Fig. 4a) implying that no deformations take place until the plastic collapse load is attained. The cross-section of the arch is such that the attainment of the plastic capacity takes place prior to local buckling. In addition, the section must be able to deliver sufficient rotation during plastic bending in order to allow redistribution of forces. In practice, this means that only wide flange sections belonging to class 1 according to Eurocode 3 EN 1993-1-1 [20] will suffice. The influence of shear forces is not taken into account, since its presence is only of influence for arches with very short spans and large section heights. An overestimation of the plastic collapse load of only $4 \%$ was observed by Cohn and Abdel-Rohman [12] when the influence of shear forces was omitted for a fixed arch subjected to a central point load. Positive values of moments correspond to tensile stresses at the inner fibers of the arch (sagging moments). Compressive forces and tensile forces in the arch are denoted as negative and positive, respectively.

\subsection{Yield contour and normality rule}

The full plastic moment is reduced due to the presence of axial forces as characterized by a so-called yield contour. Although an accurate description of the yield contour is available in the literature, the contour for the I-sections under investigation is approximated by a simple bi-linear relationship. For an I-section bent about its major axis the yield contour $\psi$ can be expressed as follows:

$$
\begin{array}{ll}
\psi=\left|\frac{M}{M_{\mathrm{pl}}}\right|-1.0=0 & \text { for } 0 \leqslant\left|\frac{N}{N_{\mathrm{pl}}}\right| \leqslant 0.153 \\
\psi=1.18\left(1.0-\left|\frac{N}{N_{\mathrm{pl}}}\right|\right)\left|\frac{M}{M_{\mathrm{pl}}}\right|=0 & \text { for } 0.153 \leqslant\left|\frac{N}{N_{\mathrm{pl}}}\right| \leqslant 1.0
\end{array}
$$

in which $M_{\mathrm{pl}}$ is the full plastic moment, $M$ is the bending moment, $N$ is the axial force and $N_{\mathrm{pl}}$ is the full axial force capacity or squash load of the section. As the yield contour is symmetric with respect to the coordinate axes, only one quadrant is shown in Fig. 4(b). The

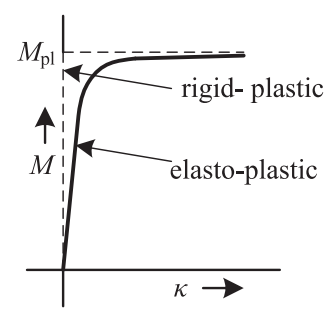

(a) plastic hinge behavior

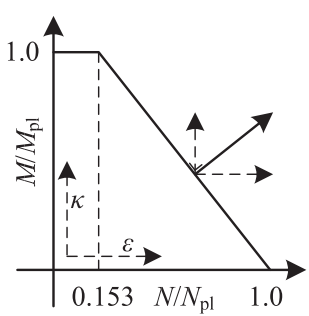

(b) yield contour

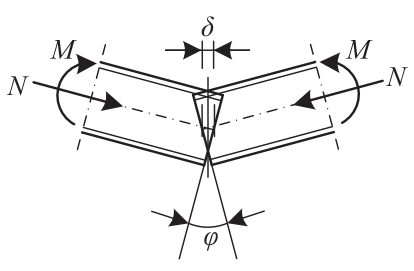

(c) plastic hinge in I-section

Fig. 4. Moment-curvature diagram, yield contour and plastic hinge under positive bending moment and compressive force. 
finite rotation $(\phi)$, contraction $(\delta)$, curvature $(\kappa)$ and axial strain $(\varepsilon)$ are related to one another by the normality rule (Fig. $4 \mathrm{~b}$ and c):

$\frac{d M}{d N}=\frac{\partial \psi / \partial N}{\partial \psi / \partial M}=-\frac{\epsilon}{\kappa}= \pm \frac{1.18 M_{\mathrm{pl}}}{N_{\mathrm{pl}}}= \pm \frac{\delta}{\varphi}$ for $0.153 \leqslant\left|\frac{N}{N_{\mathrm{pl}}}\right| \leqslant 1$

$\frac{d M}{d N}=0 \quad$ for $0 \leqslant\left|\frac{N}{N_{\mathrm{pl}}}\right| \leqslant 0.153$

The upper sign corresponds to the case when the moments and normal forces in the plastic hinge have the same sign (being either positive or negative) and the lower sign holds true when the moments and normal forces have opposite sign. The suggested approximation of the plastic moment capacity by a bi-linear curve is quite acceptable for structural design and has been proposed earlier: Trahair et al. [21]. An identical approximation of the reduced full plastic moment for arches was used earlier by Trahair et al. [14].

\section{Analyses}

\subsection{Pin-supported arch with central point load}

Symmetrical boundary conditions are imposed so that only one half of the arch need be considered (Fig. 5a). The arch geometry is expressed by the arch radius $R$ and subtended angle $2 \gamma$. It is assumed that plastic hinge no. 1 at $\theta=\theta_{1}=0$ has a reduced plastic moment capacity $M_{\mathrm{pl1} \text {;red }}$ and plastic hinge at $\theta=\theta_{2}$ has a reduced plastic moment capacity $M_{\mathrm{pl} 2 \text {;red }}$ (Fig. 5b) due to the presence of normal force $N_{1}$ and $N_{2}$, respectively, where $\theta$ is the angular coordinate for which $0 \leqslant \theta \leqslant \gamma$. The reduced plastic moment capacity of all hinges is based on Eq. (1). Replacing plastic hinge no.1 by a reacting moment, $M_{\mathrm{pl1} \text {;red }}$, the vertical $\left(R_{B V}\right)$ and horizontal reaction forces $\left(R_{\mathrm{AH}}, R_{\mathrm{BH}}\right)$ are determined from equilibrium conditions as follows:

$R_{\mathrm{BV}}=1 / 2 F \quad R_{\mathrm{AH}}=R_{\mathrm{BH}}=\frac{1 / 2 F R \sin \gamma-M_{\mathrm{pl} 1 ; \mathrm{red}}}{R(1-\cos \gamma)}$

Since no horizontal loads act on the arch, the horizontal reaction force at the support equals the compressive force in the plastic hinge at the crown:

$R_{\mathrm{BH}}=N(\theta=0)=-N_{1}$

Substituting Eq. (5) into (4) gives a formula for the plastic collapse load when a first estimate for $N_{1}$ is made:

$F_{\text {est }}=\frac{2\left(M_{\mathrm{pl} 1 ; \mathrm{red}}+N_{1} R(\cos \gamma-1)\right)}{R \sin \gamma}$

The bending moment and compressive force distribution along the arch-rib are described as follows:

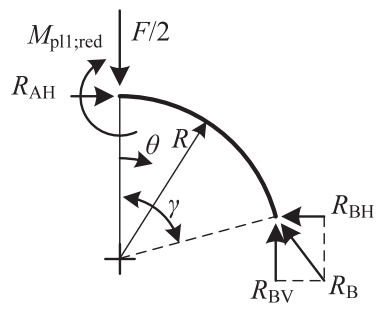

(a) Geometry and loading

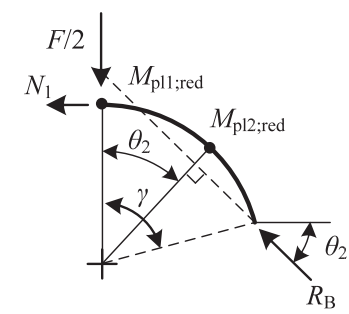

(b) Funicular line and plastic hinges
Fig. 5. Half-arch of symmetric structure.

$$
\begin{aligned}
& M(\theta)=M_{\mathrm{pl} 1 \text { red }}+R_{\mathrm{AH}} R(1-\cos \theta)-1 / 2 F R \sin \theta \\
& N(\theta)=-R_{\mathrm{BH}} \cos \theta-R_{\mathrm{BV}} \sin \theta
\end{aligned}
$$

The bending moment distribution is based on the assumption that only plastic hinge 1 has been formed. In order to reduce the arch to a collapse mechanism an extra hinge is assumed at angular coordinate $\theta_{2}$ where the bending moment equals the reduced plastic moment.

$M\left(\theta_{2}\right)=M_{\mathrm{pl} 2 ; \mathrm{red}}$

Combining (4), (7), (9) and solving for $F$ (which then is the plastic collapse load $F_{\mathrm{pl}}$ ) results in the plastic collapse load as a function of the reduced bending moment capacity of the plastic hinges:

$F_{\mathrm{pl}} \frac{2\left(M_{\mathrm{pl} 2 \text {;ed }}-\left(M_{\mathrm{pl} 1 \text {;red }}+M_{\mathrm{pl} 2 \text { red }}\right) \cos \gamma+M_{\mathrm{pl} 1 ; \mathrm{red}} \cos \theta_{2}\right)}{R\left(\sin \left(\gamma-\theta_{2}\right)-\sin \gamma+\sin \theta_{2}\right)}$

The location of the plastic hinge between the crown and the support can be obtained by solving for $\theta_{2}$ from the equation $d F_{\mathrm{pl}} /$ $d \theta_{2}=0$ resulting in:

$\theta_{2}=\arccos \frac{-M_{\mathrm{pl} 1 ; \text { red }} M_{\mathrm{pl} 2 \text {;red }}+M_{\mathrm{pl} 1 ; \text { red }} C \cos \gamma+4 \sqrt{M_{\mathrm{pl} 2 \text {;red }}} C^{3 / 2} \cos (1 / 2 \gamma) \sin ^{2}(1 / 2 \gamma)}{M_{\mathrm{pl} 1 ; \text {;red }}^{2}+2 M_{\mathrm{pl} 1 \text {; red }} M_{\mathrm{pl} 1 ; \text { red }}+2 M_{\mathrm{pl} 2 \text {; red }}^{2}-2 M_{\mathrm{pl} 2 \text {; red }} C \cos \gamma}$

where

$C=M_{\mathrm{pl} 1 ; \mathrm{red}}+M_{\mathrm{pl} 2 ; \mathrm{red}}$

The second plastic hinge emerges at the location of the maximum negative or hogging moment. This location coincides with the location where the tangent to the arch geometry is equal to the gradient of the funicular line (Fig. 5b). The normal force in hinge 2 equals the compressive action in the funicular line:

$N_{2}=N\left(\theta=\theta_{2}\right)=\sqrt{R_{\mathrm{BH}}^{2}+R_{\mathrm{BV}}^{2}}=R_{\mathrm{B}}$

An iterative procedure is required to determine the collapse load since the compressive force at the crown $N_{1}$ and the corresponding reduced plastic moment $M_{\mathrm{pl} 1 \text {;red }}$ are not known in advance. A first assumption for the compressive force at the crown produces a first estimate of $M_{\mathrm{p} 11 ; \text { red }}$ and thus a first plastic collapse load $F_{\text {est }}$ from (6). Subsequently the compressive force at the second hinge $\mathrm{N}_{2}$ is determined by substituting $F_{\text {est }}$ for $F$ into Eq. (4) and employing Eq. (13). The accompanying reduced plastic moment $M_{\mathrm{pl} 2 \text {;red }}$ can be obtained from the $M-N$ relationship in (1), and subsequently $F_{\mathrm{pl}}$ can be determined with Eq. (10). Two different plastic collapse loads are found: $F_{\mathrm{pl}}$ and $F_{\text {est }}$. The possible mismatch between $F_{\mathrm{pl}}$ and $F_{\text {est }}$ is caused by an erroneous approximation of $N_{1}$ and requires a second assumption for the normal force $N_{1}$ to start the procedure again. An accurate estimate of $N_{1}$ can be made with the (iterative) bisection method (Fig. 6). When $N_{1}$ is assumed too small: $F_{\text {est }}>F_{\mathrm{pl}}$. If $N_{1}$ is assumed too large: $F_{\text {est }}<F_{\mathrm{pl}}$. When the difference between $F_{\mathrm{pl}}$ and $F_{\text {est }}$ is within a specified tolerance $e$, the normal force $N_{1}$ at the onset of plastic collapse is found and the iterations are stopped. For all analyses $e$ was set at 0.001 . The plasticity condition requires that the reduced plastic moment of every cross-section along the arch is not exceeded. This is verified by:

$M(\theta) \leqslant\left|M_{\mathrm{pl1} ; \mathrm{red}}(\theta)\right|$

The examination of the kinematic admissibility is given in Section 3.4 .

\subsection{Pin-supported arch with uniformly distributed load}

Analogously to an arch subjected to a central point load applied at the crown, the reaction forces for an arch with a uniformly distributed load can be obtained from equilibrium equations (Fig. 7a). 


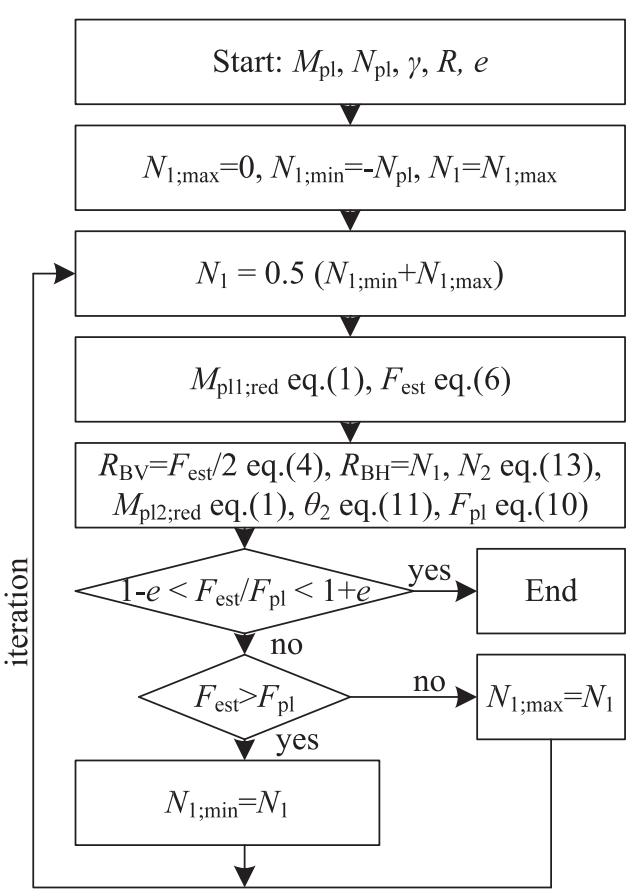

Fig. 6. Flow chart of bisection method for arch with a central point load with corresponding equation numbers.

$R_{\mathrm{BV}}=q R \sin \gamma \quad R_{\mathrm{AH}}=R_{\mathrm{BH}} \frac{1 / 2 q(R \sin \gamma)^{2}-M_{\mathrm{pl} 1 ; \mathrm{red}}}{R(1-\cos \gamma)}$

Since $R_{\mathrm{BH}}=-N_{1}$, a first estimate of the plastic collapse load $\left(q_{\mathrm{est}}\right)$ can be made when adopting a value for $N_{1}$ :

$q_{\mathrm{est}}=\frac{2\left(M_{\mathrm{pl} 1 ; \mathrm{red}}-N_{1} R+N_{1} R \cos \gamma\right)}{R^{2}(\sin \gamma)^{2}}$

The bending moment $M$ and the axial compression $N$ along the arch can be calculated as

$M(\theta)=M_{\mathrm{pl} 1 \text {; red }}+R_{\mathrm{BH}} R(1-\cos \theta)-1 / 2 q R^{2} \sin \theta$

$N(\theta)=-R_{\mathrm{BH}} \cos \theta-q R(\sin \theta)^{2}$

Hinge locations are at the crown and between the crown and the support, similar to a pin-supported arch subjected to a central point load. Due to symmetric loading conditions it can be assumed that the first hinge will form at the crown, and two subsequent hinges will develop simultaneously between the crown and supports (Fig. 7b). Hence Eq. (9) also applies to pin-supported arches subjected to a uniformly distributed load. Employing Eqs. (9), (15), (17) and solving for $q$ (which is then the plastic collapse load $\left.q_{\mathrm{pl}}\right)$ results in

$q_{\mathrm{pl}}=\frac{4\left(M_{\mathrm{pl} 1 ; \mathrm{red}}+M_{\mathrm{pl} 2 ; \mathrm{red}}\right) /\left(\cos \theta_{2}-1\right)+2 M_{\mathrm{pl} 1 ; \mathrm{red}} / \sin (\gamma / 2)^{2}}{2 R^{2}\left(\cos \gamma-\cos \theta_{2}\right)}$

By setting $d q_{\mathrm{pl}} / d \theta_{2}=0$ and solving for $\theta_{2}$ the location of the hinge between the crown and the support can be obtained

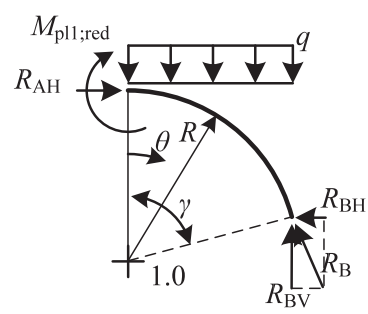

(a) Geometry and loading

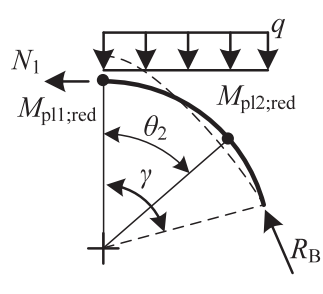

(b) Funicular line and plastic hinges
Fig. 7. Half-arch of symmetric structure.

Since the acting normal force at the crown $N_{1}$ is not known beforehand, an iterative procedure is required to arrive at the plastic collapse load. With a first estimate of $N_{1}, M_{\mathrm{pl1} \text {;red }}$ and $q_{\text {est }}$ can obtained through Eqs. (1) and (16), respectively. Subsequently the compressive force at plastic hinge no. 2 can be determined. For an arch with a central point load the compressive action at hinge no. 2 is not influenced by the angular coordinate $\theta$, as featured by Eq. (13). However, this is not true for an arch with a uniformly distributed load. Due to the non-linear relationship between $\mathrm{N}_{2}$ and $\theta_{2}$ the axial force at hinge no. 2 can only be determined by adopting an additional iteration procedure within the overall iteration loop. First an estimate of $\mathrm{N}_{2}$ is made, enabling an approximation of the reduced plastic moment capacity $M_{\mathrm{pl2} \text {;red }}$ (Fig. 8a). Subsequently $\theta_{2}$ is determined by substituting $M_{\mathrm{pl} 1 \text {;red, }} M_{\mathrm{pl} 2 \text {;red }}$ and $\gamma$ into Eq. (20), see Fig. 8b. By substituting $q_{\text {est }}$ in (15) to compute the reaction forces and using the obtained value for $R_{\mathrm{BH}}$ in Eq. (18), the normal force $N$ is expressed as function of $q_{\text {est. }}$. The normal

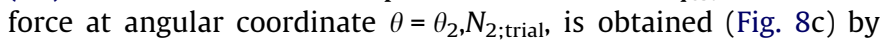
substituting $\theta_{2}$ for $\theta$ into this expression for the normal force:

$N_{2 ; \text { trial }}=\frac{1 / 2 q_{\mathrm{est}}(R \sin (\gamma))^{2}-M_{\mathrm{pl} 1 ; \text { red }}}{R(1-\cos (\gamma))} \cos \left(\theta_{2}\right)-q_{\mathrm{est}} R \sin \left(\theta_{2}\right)^{2}$

$N_{2 \text {;rial }}$ is compared to the first estimate of $N_{2}$ (Fig. $8 \mathrm{a}-\mathrm{C}$ ), and the loop starts again. The iteration procedure is performed with the bisection method. Subsequently, the ratio between $N_{2}$ and $N_{2}$;trial

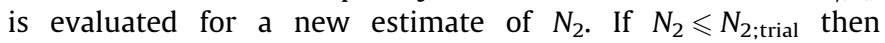

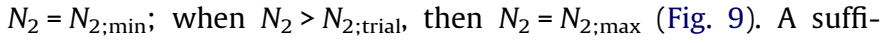
ciently accurate approximation for $N_{2}$ is found when the ratio between $N_{2} / N_{2 \text {;rial }}$ is within the specific tolerance limit $e$ and the iteration procedure for $N_{2}$ is terminated.

As $M_{\mathrm{pl} 2 \text {;red }}$ and $\theta_{2}$ are known, in addition to $M_{\mathrm{pl1} \text {;red, the plastic }}$ collapse load $q_{\mathrm{pl}}$ can now be determined from Eq. (19). With $q_{\mathrm{est}}$ and $q_{\mathrm{pl}}$ two values representing the collapse load of an arch with a uniformly distributed load are found. Any mismatch between both values is caused by an erroneous estimate of $N_{1}$ at the beginning. A more accurate estimate of $N_{1}$ is made with the bisection method (Fig. 9). When $N_{1}$ is assumed too small: $q_{\mathrm{est}}>q_{\mathrm{pl}}$. If $N_{1}$ is assumed too large: $q_{\mathrm{est}}<q_{\mathrm{pl}}$. Each subsequent estimate of $N_{1}$ will restart the iteration procedure for $N_{2}$. When the difference between $q_{\mathrm{pl}}$ and $q_{\mathrm{est}}$ is within a specified tolerance limit $e$ the normal force $N_{1}$ at the onset of plastic collapse is found and the iterations are stopped.

Since two iterative procedures are implemented for an arch with a uniformly distributed load there is a possibility that an approximation of $N_{1}$ can lead to malfunctioning of the second

$\theta_{2}=\arccos \frac{-M_{\mathrm{pl} 2 \text { red }}+\sqrt{M_{\mathrm{pl} 2 \text { red }}\left(M_{\mathrm{pl} 1 ; \mathrm{red}}+M_{\mathrm{pl} 2 \text {;red }}\right)}+\left(M_{\mathrm{pl} 1 ; \text { red }}+M_{\mathrm{pl} 2 \text { red }}-\sqrt{M_{\mathrm{pl} 2 \text { red }}\left(M_{\mathrm{pl} 1 ; \text { red }}+M_{\mathrm{pl} 2 \text {;red }}\right)}\right) \cos \gamma}{M_{\mathrm{pl} 1 ; \mathrm{red}}}$ 


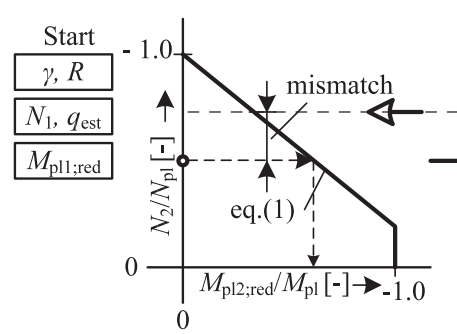

(a) $M_{\text {pl2;red }}-N_{2}$ Curve

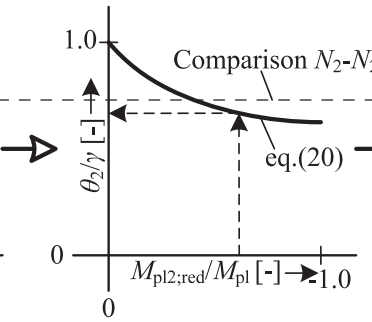

(b) $M_{\mathrm{pl} 2 ; \mathrm{red}}-\theta_{2}$ Curve

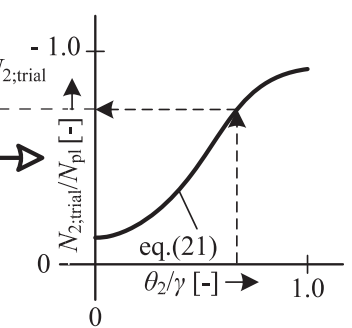

(c) $N_{2 \text {;rial }}-\theta_{2}$ Curve

Fig. 8. Iteration loop to obtain $N_{2}$ and $\theta_{2}$.

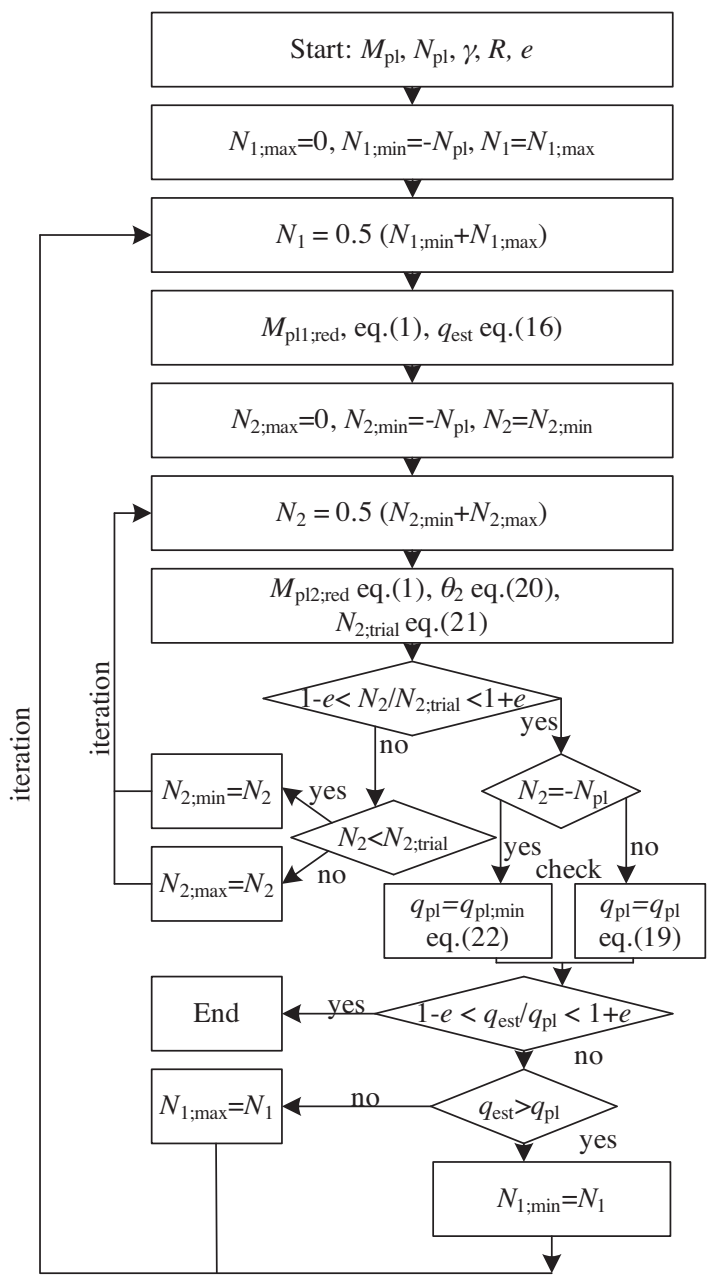

Fig. 9. Flow chart of bisection method for arch with a uniformly distributed load with corresponding equation numbers.

iterative procedure. Such a situation occurs for shallow arches when in iteration $i$ an underestimate of $N_{1}$ (overestimation of compressive force at crown) produces a value for $N_{2}$ equal to $-N_{\mathrm{pl}}$, which in turn results in a value for $M_{\mathrm{pl} 2 \text {;red }}=0$, a value of $\theta_{2}=\gamma$ and an infinite value for $q_{\mathrm{pl}}$. An infinite value will cause the iterative procedure to close down. A check was implemented in order to avoid premature termination of the iterative procedure due to infinite values of $q_{\mathrm{pl}}$ : if $N_{2}$ equals $-N_{\mathrm{pl}}$, in iteration $i$ then $q_{\mathrm{pl}}$ is no longer obtained by substituting $M_{\mathrm{pl} 2 \text {;red }}=0$ and $\theta_{2}=\gamma$ into Eq. (19), (which would result in an infinite value for $q_{\mathrm{pl}}$ ) but by taking the limit and ignoring the axial force at the crown:

$$
\begin{aligned}
q_{\mathrm{pl} ; \text { min }} & =\underset{M_{\mathrm{pl} 2 ; \mathrm{red}} \rightarrow 0, \theta_{2} \rightarrow 0}{q_{\mathrm{pl}}}\left(M_{\mathrm{pl} 2 ; \mathrm{red}}, \theta_{2}, M_{\mathrm{pl} 1 ; \text { red }}=M_{\mathrm{pl}}\right) \\
& =\frac{M_{\mathrm{pl}}}{\left(R^{2} \sin (\gamma / 2)^{4}\right)}
\end{aligned}
$$

This will automatically initiate a new approximation of $N_{1}$ in iteration $i+1$ which is larger (smaller compressive force) than the previous iteration $\left(N_{1}(i)<N_{1}(i+1)\right)$, rendering a more appropriate value for $N_{2}$, and $q_{\mathrm{pl}}$. To check the plasticity conditions, Eq. (14) is employed.

\subsection{Fixed arch with central point load}

For a fixed arch the internal force distribution is different compared to a pin-supported arch. Moreover, the fixation at the abutments allows the development of two extra hinges at plastic collapse. When considering one half of the arch, the plastic hinges at the crown and at the support can be replaced by reacting bending moments, denoted by $M_{\mathrm{pl} 1 \text {;red }}$ and $M_{\mathrm{pl} 3 \text {;red, respectively }}$ (Fig. 10a).

The 'free' bending moment distribution at the onset of plastic collapse (Fig. 10c) can be divided into a reactant moment distribution (Fig. 10d) and an acting moment distribution (Fig. 10e). The first is caused by reacting moments at the crown $M_{\mathrm{pl1} \text {;red }}$ and abutment $M_{\mathrm{pl} 3 \text {;red, }}$ replacing the plastic hinges. As it assumed that both reacting moments are equal they do not cause any reaction forces at the supports and compressive actions in the arch-rib. The acting moment distribution is the result of the central point load at the crown $(F / 2)$ and renders a funicular line inclined to the horizontal plane by angle $\gamma / 2$. Based on $N_{1}=-R_{\mathrm{BH}}$ and decomposing the reaction forces from the acting moments at the support it can be seen that the compressive forces at the crown $N_{1}$ and at the support $N_{3}$ are equal (Fig. 10b and f). This is in accordance with the assumption that both reactant moments are equal. The following simplifications can therefore be made:

$M_{\mathrm{pl} 3 \text {;ed }}=M_{\mathrm{pl} 1 \text {;ed }}$

$N_{3}=N_{1}$

$\theta_{2}=\gamma / 2$

Considering equilibrium of parts the vertical reaction force and horizontal force can be determined as follows (Fig. 10a):

$$
\begin{aligned}
R_{\mathrm{BV}} & =1 / 2 F \quad R_{\mathrm{AH}}=R_{\mathrm{BH}}=\frac{1 / 2 F R \sin \gamma-M_{\mathrm{pl} 3 \text { red }}+M_{\mathrm{pl1} ; \mathrm{red}}}{R(1-\cos \gamma)} \\
& =\frac{1 / 2 F R \sin \gamma}{R(1-\cos \gamma)}
\end{aligned}
$$

When employing horizontal equilibrium, Eq. (26) can be rewritten such that a first approximation of the horizontal force $N_{1}$ produces an estimate of the plastic collapse load $F_{\text {est }}$ as follows:

$F_{\text {est }}=\frac{2 N_{1} R(\cos \gamma-1)}{R \sin \gamma}$ 

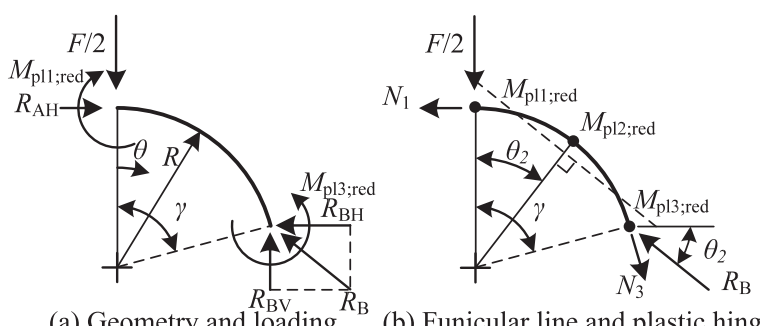

$\begin{array}{ll}\text { (a) Geometry and loading } & \text { (b) Funicular line and plastic hinges }\end{array}$

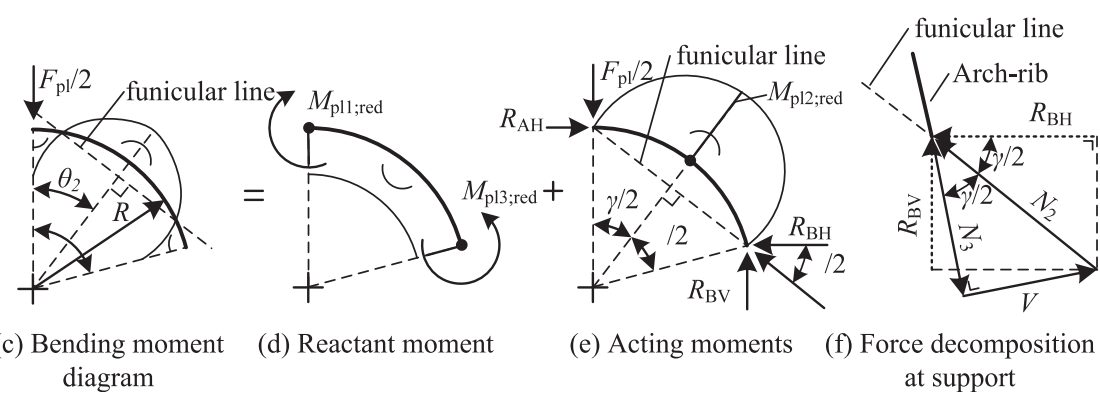

Fig. 10. Half-arch of symmetric structure, bending moment distribution and force decomposition at support.

The bending moment distribution and normal force distribution can be described by Eqs. (7) and (8), respectively. The fixed arch is reduced to a mechanism when a third hinge appears at angular coordinate $\theta_{2}$ where the hogging moment equals the reduced plastic moment capacity $M_{\text {pl2;red }}$ (Fig. 10b), Eq. (9). Combining Eq. (26) with (7) and (9) yields the plastic collapse load (renaming $F$ by $F_{\mathrm{pl}}$ ) when the 5 hinges are formed in the arch. Using (23) and (25) this can be further simplified to:

$F_{\mathrm{pl}}=\frac{2\left(M_{\mathrm{pl} 2 ; \mathrm{red}}+M_{\mathrm{pl} 3 ; \mathrm{red}}-\left(M_{\mathrm{pl} 1 \text { red }}+M_{\mathrm{pl} 2 \text {;red }}\right) \cos \gamma\right)}{R(-\sin \gamma+2 \sin (\gamma / 2))}$

The compressive action at the second plastic hinge $N_{2}$ can be determined with (13) and (26) by substituting $F_{\text {est }}$ for $F$ which subsequently can be used to find the reduced plastic moment capacity $M_{\text {pl2;red. }}$

A first assumption for the compressive force at the crown $N_{1}$ allows an estimate of the plastic moment capacity at the crown $M_{\text {pl1;red }}$ with Eq. (1) and an estimate for $F_{\text {est }}$ with Eq. (27). $F_{\text {est }}$ is then used to obtain the reaction forces $R_{\mathrm{BV}}$ and $R_{\mathrm{BH}}$ with Eq. (26). These reaction forces are subsequently substituted into Eq. (13) to evaluate the compressive force at the second hinge $N_{2}$, which in turn can be used to obtain $M_{\mathrm{pl} 2 \text {;red. }}$ Based on the equality $M_{\mathrm{pl} 1 \text {;red }}=M_{\mathrm{pl3} \text {;red }}$ the plastic collapse load $F_{\mathrm{pl}}$ can be determined with Eq. (28). Similarly as for the previous two load cases, any value of $N_{1}$ will yield two different collapse loads: $F_{\text {est }}$ and $F_{\mathrm{pl}}$. The discrepancy between $F_{\mathrm{est}}$ and $F_{\mathrm{pl}}$ is caused by an erroneous approximation of $N_{1}$ and requires a second assumption for $N_{1}$ to start the procedure again. The bisection method is used to make an accurate estimate for $N_{1}$. The same flow scheme as presented in Fig. 6 for the pin-supported arch can be employed, but the equilibrium equations must be altered according to Table 1 to render the method applicable for fixed arches. If $N_{1}$ is assumed too large:

Table 1

Equilibrium equations for a pin-supported arch and a fixed arch subjected to a central point load.

\begin{tabular}{lcc}
\hline & Pin-supported & Fixed \\
\hline$R_{\mathrm{BH}}, R_{\mathrm{BV}}$ & $(4)$ & $(26)$ \\
$\theta_{2}$ & $(11)$ & $(25)$ \\
$F_{\mathrm{pl}}$ & $(10)$ & $(28)$ \\
$F_{\mathrm{est}}$ & $(6)$ & $(27)$ \\
\hline
\end{tabular}

$F_{\text {est }}<F_{\mathrm{pl}}$, when $N_{1}$ is assumed too small: $F_{\text {est }}>F_{\mathrm{pl}}$ (taking into account the sign convention for compressive forces). The iterations are stopped when the difference between $F_{\text {est }}$ and $F_{\mathrm{pl}}$ is within the tolerance limit $e$. The reduced plastic moment of every crosssection should not be exceeded by the acting moments which must be verified through Eq. (14)

\subsection{Kinematic admissibility}

In the preceding sections a sufficient number of hinges was introduced which initiates a plastic collapse mechanism. However, in order to make sure that the prescribed mechanism will indeed develop and that the solution is physically meaningful, its associated collapse mechanism must be checked for kinematic admissibility. The rotations $\varphi_{i}$ and contractions $\delta_{i}$ in plastic hinge i are shown in Fig. 11, where subscript i denotes the number of the plastic hinges according to Fig. $3 \mathrm{c}$ and $\mathrm{d}$. The size of the deformations at plastic collapse load cannot be determined, since the material displays plastic yielding under constant force. Therefore, the rotations and contractions are normalized with respect to $\varphi_{1}$.

The kinematic admissibility requires that for the prescribed mechanism to develop, the following conditions have to be met (Fig. 11):

$\Delta_{\text {ver }} / \varphi \geqslant 0$

$\varphi_{2} / \varphi_{1} \geqslant 0$

$\varphi_{3} / \varphi_{1} \geqslant 0$

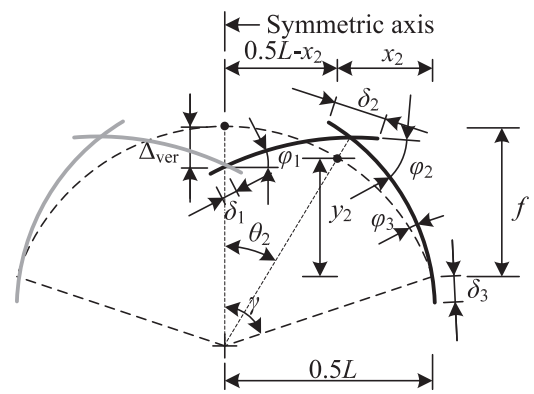

Fig. 11. Collapse mechanism (deformations and rotations shown as positive). 
Eq. (29) ensures that the crown moves in the same direction as the acting load, resulting in a positive plastic collapse load. Eqs. (30) and (31) ensure that negative (hogging) moments occur at plastic hinge 2 and positive (sagging) moments at plastic hinge 3 . The downward displacement of the center of the arch can be obtained by considering the effect of each partial displacement, see Chakrabarty [13]:

$\Delta_{\mathrm{ver}}=\left(1 / 2 L-x_{2}\right) \varphi_{2}-1 / 2 L \varphi_{3}+\delta_{2} \sin \theta_{2}+\delta_{2} \sin \gamma$

where $L$ and $x_{2}$ are the horizontal span length and horizontal position of plastic hinge no. 2 respectively. Based on geometry considerations the following equations hold:

$L=2 R \sin \gamma \quad x_{2}=1 / 2 L-R \sin \theta_{2}$

In view of the normality rule in conjunction with the sign convention, the following relations can be derived:

$-\frac{\varepsilon_{1}}{\kappa_{1}}=\frac{\delta_{1}}{\varphi_{1}}=c_{1} \quad \frac{\varepsilon_{2}}{\kappa_{2}}=\frac{\delta_{2}}{\varphi_{2}}=c_{2} \quad-\frac{\varepsilon_{3}}{\kappa_{3}}=\frac{\delta_{3}}{\varphi_{3}}=c_{3}$

For a pin-supported arch without a plastic hinge at the support, $c_{3}=0$. For a fixed arch $c_{3}=c_{1}$. The closure of the arch segments is given by the following relationship:

$\varphi_{3}=\varphi_{2}-\varphi_{1}$

The condition of zero horizontal displacement at the center of the arch can be obtained considering the geometry as follows:

$\Delta_{\text {hor }}=f \varphi_{3}\left(f-y_{2}\right) \varphi_{2}+\delta_{1}+\delta_{2} \cos \theta_{2}+\delta_{3} \cos \gamma=0$

where $f$ is the rise of the arch and $y_{2}$ the vertical position of plastic hinge no. 2 (Fig. 11). The rise of the arch and the vertical position of the second hinge can be obtained by the following equation:

$f=R(1-\cos \gamma) \quad y_{2}=f-R\left(1-\cos \theta_{2}\right)$

Using Eqs. (34) and (35) in conjunction with (36), Eq. (30) can be rewritten as:

$\frac{\varphi_{2}}{\varphi_{1}}=\frac{f-c_{1}+c_{3} \cos \gamma}{y_{2}+c_{2} \cos \theta_{2}+c_{3} \cos \gamma} \geqslant 0$

Combining (35) and (38) yields a new expression for Eq. (31):

$\frac{\varphi_{3}}{\varphi_{1}}=\frac{f-y_{2}-c_{1}-c_{2} \cos \theta_{2}}{y_{2}+c_{2} \cos \theta_{2}+c_{3} \cos \gamma} \geqslant 0$

Similarly, the kinematic requirement featured by Eq. (29) can be obtained by employing (33), (34) and (38):

$$
\begin{aligned}
\frac{\Delta_{\mathrm{ver}}}{\varphi_{1}}= & \frac{f-c_{1}+c_{3} \cos \gamma}{y_{2}+c_{2} \cos \theta_{2}+c_{3} \cos \gamma}\left(-x_{2}+c_{2} \sin \theta_{2}+c_{3} \sin \gamma\right) \\
& +\left(1 / 2 L-c_{3} \sin \gamma\right) \geqslant 0
\end{aligned}
$$

For a pin-supported arch Eqs. (40) and (38) must be satisfied. For a fixed arch an additional kinematic admissibility requirement is necessary: Eq. (39). These kinematic admissibility requirements will be used later to check the validity of the calculated collapse loads.

\section{Comparisons with previous studies}

Before proceeding to a comparison between the suggested iterative method and finite element calculations for wide flange sections, the iterative method is compared to design formulae from earlier studies. The comparisons are supplemented with the kinematic admissibility requirements presented in Section 3.4.
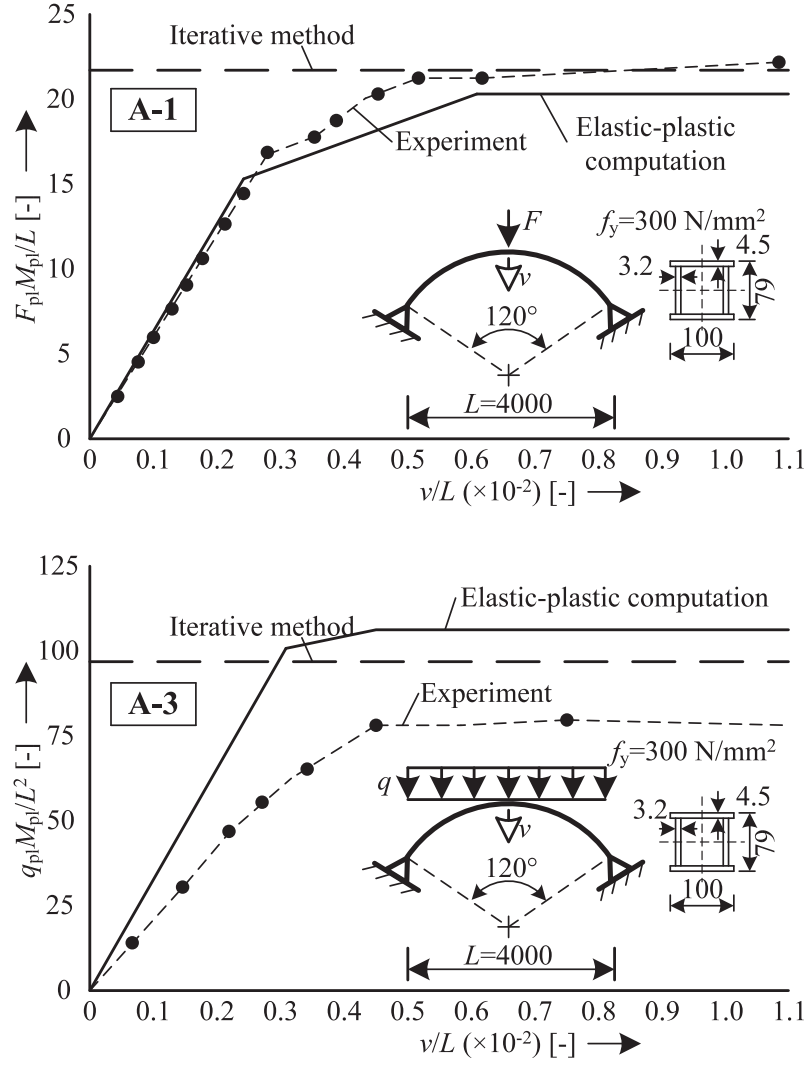

Fig. 12. Plastic collapse load obtained by iterative method and according to Maeda and Fuijmoto.

\subsection{Experiments by Maeda and Fujimoto}

Full-scale tests on circular arches made from welded boxsections were performed by Maeda and Fujimoto [11] (Fig. 12). The arches had a span $L$ of $4000 \mathrm{~mm}$ and were constrained against out-of-plane deflections ensuring that the in-plane plastic collapse load would be attained. Experimental collapse loads $\left(F_{\mathrm{pl}}(\operatorname{Exp})\right)$ from pin supported arches subjected to a central point load at the crown and a uniformly distributed load are presented for comparison with the proposed iterative method ( $F_{\mathrm{pl}}$ (Iterative method)) in Table 2. The ratio is computed as: $F_{\mathrm{pl}}(\operatorname{Exp}) / F_{\mathrm{pl}}$ (Iterative method). It can be seen that the iterative method is able to approximate the experimental collapse loads for a central point load quite well. However it overestimates the plastic collapse loads for arches with uniformly distributed loading.

The experimentally obtained load-deflection curves for tests A-1 and A-3 are shown in Fig. 12, in addition to numerical elastic-plastic computations by Maeda and Fujimoto. The plastic collapse load obtained by the iterative method is displayed by the horizontal dashed line. It can be seen that the numerical analyses are able to replicate the experimental load-deflection curve quite well for the arch with a central point load. Larger discrepancies are observed for the uniformly distributed load. Both the iterative method and the numerical computations overestimate the experimentally obtained plastic collapse load. In all cases the kinematic admissibility requirements were met.

\subsection{Chakrabarty}

The proposed iterative method is also compared to analytically obtained collapse loads presented by Chakrabarty [13]. A circular arch with developed arch length of $S=8 \mathrm{~m}$ is analyzed for a solid 
Table 2

Plastic collapse load obtained from iterative method and [11].

\begin{tabular}{|c|c|c|c|c|c|c|c|}
\hline \multirow[t]{3}{*}{ Test } & \multirow[t]{3}{*}{$2 \gamma\left({ }^{\circ}\right)$} & \multirow[t]{3}{*}{ Loadcase } & \multicolumn{3}{|c|}{ Iterative method } & \multirow[t]{3}{*}{ Exp. [11] } & \multirow[t]{3}{*}{ Ratio } \\
\hline & & & & \multicolumn{2}{|c|}{ Kinematic admissibility } & & \\
\hline & & & & $\varphi_{2} / \varphi_{1}$ & $\Delta_{\text {ver }} / \varphi_{1}$ & & \\
\hline A-1 & 120 & Central point load & $67.6 \mathrm{kN}$ & $>0$ & $>0$ & $68.3 \mathrm{kN}$ & 1.01 \\
\hline A-3 & 120 & Uniformly distributed load & $76.8 \mathrm{kN} / \mathrm{m}$ & $>0$ & $>0$ & $63.6 \mathrm{kN} / \mathrm{m}$ & 0.83 \\
\hline B-1 & 60 & Central point load & $65.0 \mathrm{kN}$ & $>0$ & $>0$ & $63.8 \mathrm{kN}$ & 0.98 \\
\hline B-3 & 60 & Uniformly distributed load & $85.9 \mathrm{kN} / \mathrm{m}$ & $>0$ & $>0$ & $59.5 \mathrm{kN} / \mathrm{m}$ & 0.70 \\
\hline
\end{tabular}

Table 3

Plastic collapse load [kN] obtained by iterative method and [13].

\begin{tabular}{rlllll}
\hline $2 \gamma\left(^{\circ}\right)$ & \multicolumn{2}{l}{ Iterative method } & Chakrabarty [13] & Ratio (-) \\
\cline { 2 - 4 } & \multicolumn{3}{c}{ Kinematic admissibility } & \\
\cline { 2 - 4 } & \multicolumn{2}{c}{$\varphi_{2} / \varphi_{1}$} & $\Delta_{\text {ver }} / \varphi_{1}$ & \\
\hline 45 & 4670 & $>0$ & $>0$ & 4430 & 0.95 \\
90 & 5470 & $>0$ & $>0$ & 5450 & 1.00 \\
135 & 5520 & $>0$ & $>0$ & 5530 & 1.00 \\
180 & 5590 & $>0$ & $>0$ & 5630 & 0.99 \\
\hline
\end{tabular}

rectangular cross-section. The same yield contour as adopted by Chakrabarty has been implemented, which is different from the one in Section 2.3. The arch is pin-supported and loaded by a central point load. The dimensions of the rectangular solid section are: depth $h=400 \mathrm{~mm}$; and width $b=200 \mathrm{~mm}$. The yield stress of the material is $f_{y}=235 \mathrm{~N} / \mathrm{mm}^{2}$. The subtended angle was varied between $45^{\circ}$ and $180^{\circ}$ with increments of $45^{\circ}$. The results are presented in Table 3 . The ratio is defined as $F_{\mathrm{pl}}$ (Chakrabarty)/F $F_{\mathrm{pl}}$ (Iterative method). The kinematic admissibility requirements were met for all investigated arches.

Very good agreement between the iterative method and the graphical solution as presented by Chakrabarty is observed. The discrepancy between both methods is larger for an arch with a small subtended angle.

\subsection{Cohn and Abdel-Rohman}

Cohn and Abdel-Rohman [12] investigated a single arch geometry, partly based on an earlier study carried out by Onat and Prager [7] using an in-house developed computer model. They used Imperial units which are converted here to SI units. The circular arch under investigation had a horizontal span $L=$ $12.93 \mathrm{~m}$ (42.42 ft.) and a rise $f=2.67 \mathrm{~m}(8.75 \mathrm{ft}$.), which renders a subtended angle of 90 degrees and a radius of $9.14 \mathrm{~m}$ (30 ft.). The arch section had a solid rectangular geometry $609.6 \mathrm{~mm}(2 \mathrm{ft}$.) $\times$ $304.8 \mathrm{~mm}$ ( $1 \mathrm{ft}$.) with a yield stress $f_{y}$ of $248.2 \mathrm{~N} / \mathrm{mm}^{2}$ or $36 \mathrm{ksi}$. The comparison comprises two different loading conditions and two different support conditions: pin-supported and a central point load (1), pin-supported and uniformly distributed load (2), and fixed supports with central point load (3). The collapse load of the arch with a uniformly distributed load is defined as the uniformly distributed load multiplied by the horizontal span length $L$.
A full comparison is presented in Table 4. The ratio is expressed as $F_{\mathrm{pl}}$ (Cohn and Abdel-Rohman) $/ F_{\mathrm{pl}}$ (Iterative method). In all cases the kinematic admissibility requirements were met.

The small differences btween the iterative method and results from Cohn and Abdel-Rohman [12] are attributed to the following. Cohn and Abdel-Rohman investigated rather stocky arches for which the influence of shear forces can be significant. The influence of shear forces is neglected in the authors' study, but was taken into account by Cohn and Abdel-Rohman.

\subsection{La Poutre and Snijder}

The plastic capacity of pin-supported wide flange steel arches with a central point load and with various subtended angles was investigated by La Poutre and Snijder [15] and La Poutre [16]. The arches were studied using analytical and finite element analyses (FEA). The influence of normal forces on the plastic moment capacity was not taken into account as shown in one quadrant of the yield contour in Fig. 13a. Furthermore, it was assumed that the arch fails by a sway mechanism, featuring a total of two plastic hinges at the onset of plastic collapse (Fig. 13b). The analytical and finite element analyses performed by La Poutre and Snijder [15] and La Poutre [16] are compared with the iterative method for HE 600B arches (Fig. 13c) with a yield stress of $f_{y}=291 \mathrm{~N} / \mathrm{mm}^{2}$ and varying subtended angles and arch radii. Two different yield contours are adopted for the iterative method: the yield contour presented in Section 2.3 and the yield contour shown in Fig. 13a, i.e. no influence of normal forces on the plastic moment capacity.

A full comparison is shown in Tables 5 and 6 for semi-circular arches and arches with smaller subtended angles, respectively. It can be seen that for semi-circular arches the iterative method is able to replicate the results of the analytical method and numerical computations with good accuracy, irrespective of the adopted yield contour. Ignoring the influence of normal force on the plastic moment capacity has little influence on the plastic collapse load of semi-circular steel arches and can be regarded as a useful simplification. A comparison with FEA results in Table 6 shows that the analytical model of La Poutre [16] and the iterative method, without the influence of normal forces, for arches with smaller subtended angles produce significant overestimations in plastic collapse load. The iterative method with influence of normal forces gives a better approximation of the plastic collapse load, indicating

Table 4

Plastic collapse load [kN] obtained by iterative method and [12].

\begin{tabular}{|c|c|c|c|c|c|c|c|}
\hline \multirow[t]{3}{*}{ Supports } & \multirow[t]{3}{*}{ Load case } & \multicolumn{4}{|c|}{ Iterative method } & \multirow[t]{3}{*}{ Cohn and Abdel-Rohman [12] } & \multirow[t]{3}{*}{ Ratio } \\
\hline & & & \multicolumn{3}{|c|}{ Kinematic admissibility } & & \\
\hline & & & $\varphi_{2} / \varphi_{1}$ & $\Delta_{\text {ver }} / \varphi_{1}$ & $\varphi_{3} / \varphi_{1}$ & & \\
\hline Pin-supported & Central point load & 11653 & $>0$ & $>0$ & $\mathrm{n} / \mathrm{a}$ & 11013 & 0.95 \\
\hline Pin-supported & Uniformly distributed load & 54719 & $>0$ & $>0$ & $\mathrm{n} / \mathrm{a}$ & 49573 & 0.91 \\
\hline Fixed & Central point load & 13179 & $>0$ & $>0$ & $>0$ & 12343 & 0.94 \\
\hline
\end{tabular}




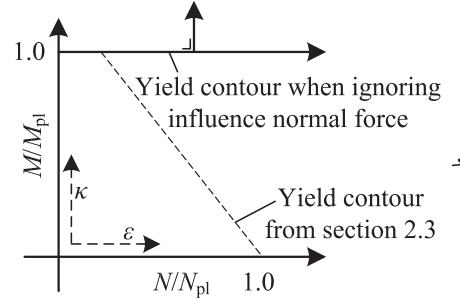

(a) Yield contour

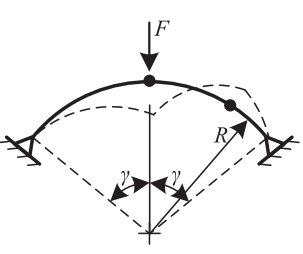

(b) sway mechanism

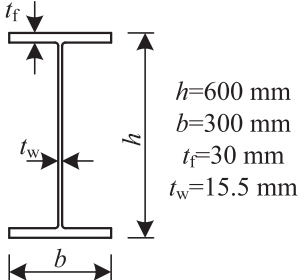

(c) cross-section HE 600B

Fig. 13. Yield contour, plastic collapse mechanism and wide flange sections used by La Poutre and Snijder [15] and La Poutre [16].

Table 5

Plastic collapse load [kN] obtained by iterative method and according [15] for HE 600B semi-circular arches.

\begin{tabular}{|c|c|c|c|c|c|c|c|c|c|}
\hline \multirow[t]{4}{*}{$R / h(-)$} & \multirow[t]{4}{*}{$2 \gamma\left({ }^{\circ}\right)$} & \multicolumn{6}{|c|}{ Iterative method } & \multicolumn{2}{|c|}{ La Poutre and Snijder } \\
\hline & & \multicolumn{3}{|c|}{ With influence of normal force } & \multicolumn{3}{|c|}{ Without influence of normal force } & \multirow[t]{3}{*}{ Analytical } & \multirow[t]{3}{*}{ FEA } \\
\hline & & & \multicolumn{2}{|c|}{ Kinematic admissibility } & & \multicolumn{2}{|c|}{ Kinematic admissibility } & & \\
\hline & & & $\varphi_{2} / \varphi_{1}$ & $\Delta_{\mathrm{ver}} / \varphi_{1}$ & & $\varphi_{2} / \varphi_{1}$ & $\Delta_{\mathrm{ver}} / \varphi_{1}$ & & \\
\hline 11.1 & 180 & 2217 & $>0$ & $>0$ & 2256 & $>0$ & $>0$ & 2260 & 2325 \\
\hline 19.9 & 180 & 1253 & $>0$ & $>0$ & 1253 & $>0$ & $>0$ & 1260 & 1344 \\
\hline 26.5 & 180 & 940 & $>0$ & $>0$ & 940 & $>0$ & $>0$ & 947 & 1003 \\
\hline
\end{tabular}

Table 6

Plastic collapse load [kN] obtained by iterative method and [16] for HE 600B arches.

\begin{tabular}{|c|c|c|c|c|c|c|c|c|c|}
\hline \multirow[t]{4}{*}{$R / h(-)$} & \multirow[t]{4}{*}{$2 \gamma\left({ }^{\circ}\right)$} & \multicolumn{6}{|c|}{ Iterative method } & \multicolumn{2}{|l|}{ La Poutre } \\
\hline & & \multicolumn{3}{|c|}{ With influence of normal force } & \multicolumn{3}{|c|}{ Without influence of normal force } & \multirow[t]{3}{*}{ Analytical } & \multirow[t]{3}{*}{ FEA } \\
\hline & & & \multicolumn{2}{|c|}{ Kinematic admissibility } & & \multicolumn{2}{|c|}{ Kinematic admissibility } & & \\
\hline & & & $\varphi_{2} / \varphi_{1}$ & $\Delta_{\text {ver }} / \varphi_{1}$ & & $\varphi_{2} / \varphi_{1}$ & $\Delta_{\mathrm{ver}} / \varphi_{1}$ & & \\
\hline 11.1 & 90 & 3201 & $>0$ & $>0$ & 4807 & $>0$ & $>0$ & 4819 & 3208 \\
\hline 19.9 & 90 & 2203 & $>0$ & $>0$ & 2670 & $>0$ & $>0$ & 2688 & 2348 \\
\hline 26.5 & 90 & 1786 & $>0$ & $>0$ & 2003 & $>0$ & $>0$ & 2019 & 1923 \\
\hline 11.1 & 135 & 2768 & $>0$ & $>0$ & 3124 & $>0$ & $>0$ & 3128 & 2876 \\
\hline 19.9 & 135 & 1713 & $>0$ & $>0$ & 1735 & $>0$ & $>0$ & 1745 & 1797 \\
\hline 26.5 & 135 & 1301 & $>0$ & $>0$ & 1301 & $>0$ & $>0$ & 1310 & 1393 \\
\hline
\end{tabular}

that the presence of normal force is significant for these arches. When comparing the analytical method of La Poutre and Snijder [15] and La Poutre [16] with the iterative method without the influence of normal force it can be seen that the iterative method produces consistently lower plastic collapse loads. This indicates that the adoption of a vertical collapse mechanism produces the lowest plastic collapse loads. The kinematic admissibility requirements were satisfied for all investigated arch configurations and yield contours.

\section{Comparison with finite element results}

\subsection{Numerical model}

Analytical solutions from the iterative method were compared to collapse loads obtained from finite element analyses (FEA). The finite element code ANSYS 11.0 was used to carry out the computations. Shell elements (SHELL181) were used to model the arch (Fig. 14). The wide flange section consists of three plates, two flanges and one web. The fillets are not modeled.

\subsubsection{Loading and boundary conditions}

In order to avoid excessively high stress concentrations at the supports, multipoint constraint elements (MPC184) are used. By defining a boundary condition at the centroid, the multipoint constraint elements impose a correct transfer of the displacements to the adjacent elements. Multipoint constraints are particularly suit- able for modeling rigid connections. The number of MPC184 elements complies with the shell element distribution over the height of the web (Fig. 15). In order to correctly model the multi point constraint, the rigid beam option was selected. The kinematic constraints are imposed with the direct elimination method. For the arch subjected to a central point load, MPC184 elements are also applied over the height of the web to facilitate load introduction.

The calculations were carried out for a steel section HE $300 \mathrm{~A}^{*}$. The asterisk * is used throughout the paper to illustrate that the modeled section is not identical to a commercially available section due to the absence of the fillets. The properties and dimensions of the HE $300 \mathrm{~A}^{*}$ arch are: yield stress $f_{y}=235 \mathrm{~N} / \mathrm{mm}^{2}$, Young's modulus $E=200,000 \mathrm{~N} / \mathrm{mm}^{2}$, yield strain $\varepsilon_{y}=0.001175$ (Fig. 16a), width of the flange $b=300 \mathrm{~mm}$, section height $h=290 \mathrm{~mm}$, flange thickness $t_{f}=14 \mathrm{~mm}$ and web thickness $t_{w}=8.5 \mathrm{~mm}$ (Fig. 16b).

\subsubsection{Mesh refinement study}

The mesh refinement study is performed such that the finer mesh is always part of the larger mesh. A HE $300 \mathrm{~A}^{*}$ with a subtended angle of $180^{\circ}$ and an arch length $S$ of $12 \mathrm{~m}$ is subjected to a central point load. The mesh refinement study is presented in Table 7. It can be seen that by increasing the mesh density the plastic collapse load decreases. The difference between a specific mesh and mesh no. 4 is tabulated in the last column. Based on the relatively small difference between mesh no. 3 and mesh no. 4, mesh 


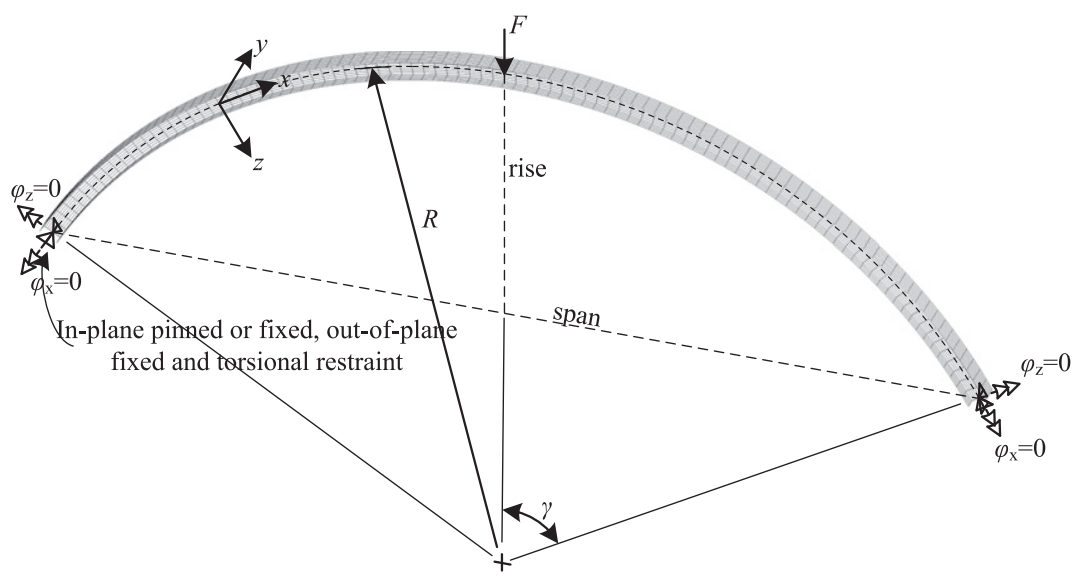

Fig. 14. Finite element model of arch with central point load.

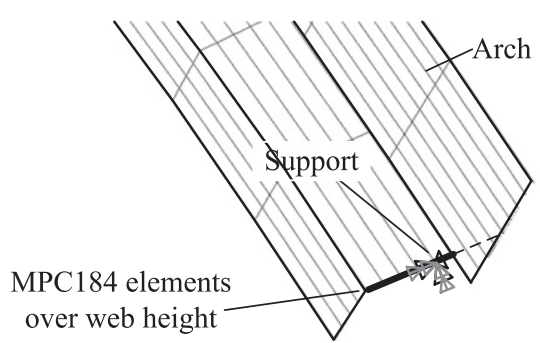

Fig. 15. Detail of arch support.

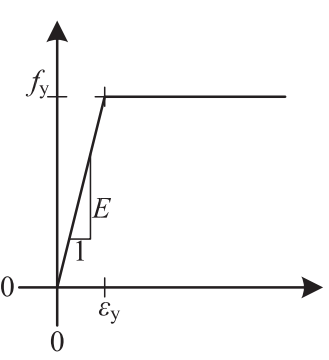

(a) stress-strain curve

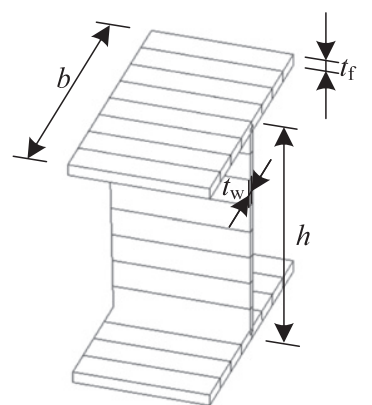

(b) cross-section
Fig. 16. Stress-strain curve and cross-section.

no. 3 is selected for further computations. The difference is computed as $\left(F_{\mathrm{pl}}(\right.$ mesh no. $)-F_{\mathrm{pl}}($ mesh no.4 $\left.)\right) / F_{\mathrm{pl}}($ mesh no.4 $) \times 100 \%$.

\subsubsection{Solution procedure}

The analyses incorporate material non-linearities, but equilibrium is defined in the undeformed state. Plasticity is characterized by the Von Mises yield criterion and the Prandtl-Reuss flow rule. The system of equilibrium equations has to be solved iteratively. The load is divided into load steps, which in turn are divided into load increments. The load increments are successively placed on the arch and by using a series of iterations equilibrium is found. For these analyses the Newton-Raphson method has been adopted in the solution phase. The convergence criterion for the out-of-balance load vector is equal to $0.05 \%$. In addition to the force norm check a convergence criterion of $0.05 \%$ was applied for the displacement increments. All analyses are load controlled where the loads act on the centerline of the cross-section. The plastic collapse load is identified by the last converged load increment. Load-
Table 7

Mesh refinement study.

\begin{tabular}{lccrrl} 
Mesh no. & \multicolumn{2}{l}{ Number of elements } & \multirow{2}{*}{$F_{\mathrm{pl}}(\mathrm{kN})$} & Difference (\%) \\
\cline { 2 - 4 } & Flanges/web & Arch length & Total & & \\
\hline 1 & 2 & 24 & 144 & 685550 & 12.8 \\
2 & 4 & 48 & 576 & 633750 & 4.24 \\
3 (adopted) & 8 & 96 & 2304 & 622200 & 2.35 \\
4 & 16 & 192 & 9216 & 608000 & - \\
\hline
\end{tabular}

deflection characteristics are depicted in Fig. 17 for HE 300A* arches with two different subtended angles. The loads for the pin-supported arch with a uniformly distributed load are multiplied by the arch span $L$ in order to plot the data in the same graph as for the arch with a central point load. A fixed HE $300 A^{*}$ arch with a central load with the equivalent plastic strain distribution at plastic collapse is shown in Fig. 18 for two subtended angles. It can be seen that for the arch with $2 \gamma=120^{\circ}$, five plastic hinges are present indicating that a flexural mechanism takes place. Only three hinges are formed in the arch with $2 \gamma=20^{\circ}$ featuring a compressive mechanism.

\subsection{Pin-supported arch with central point load}

A full comparison between the finite element method and iterative method for a pin-supported $\mathrm{HE} 300 \mathrm{~A}^{*}$ section arch subjected to a central point load is given in Table 8. This was done for two arch lengths: $S=12 \mathrm{~m}$ and $S=16 \mathrm{~m}$. It can be seen that the iterative method is able to give the plastic collapse load with good accuracy. The kinematic admissibility requirements are fulfilled for all investigated angles. The ratio is defined as: $F_{\mathrm{pl}}(\mathrm{FEA}) / F_{\mathrm{pl}}$ (Iterative method).

Through a comparison between the plastic collapse loads as obtained with the iterative method and finite element analyses it can be seen that a maximum error of $5 \%$ is found. The iterative method produces more accurate results for deep arches than for shallow arches.

\subsection{Pin-supported arch with uniformly distributed load}

The same arch geometries are used to make a comparison between the iterative method and finite element analyses when they are subjected to a uniformly distributed load. The plastic collapse loads from FEA and the iterative method are shown in Table 9. Similar to the previous load case, good agreement between both methods is found. For all investigated subtended angles, the kinematic admissibility requirements are met. 

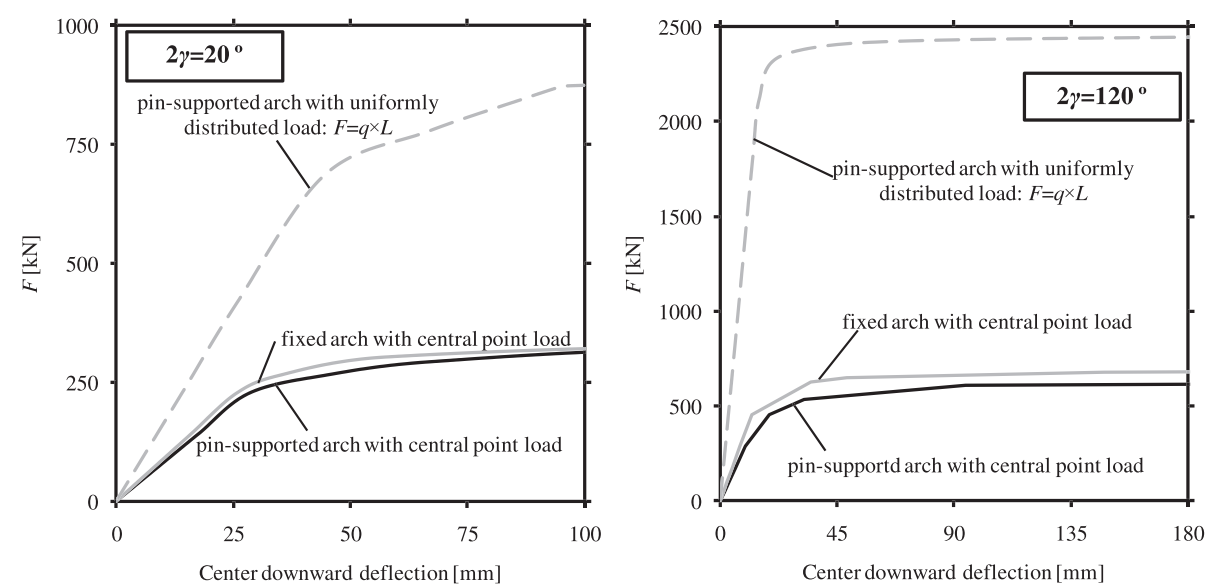

Fig. 17. Load-deflection characteristics.

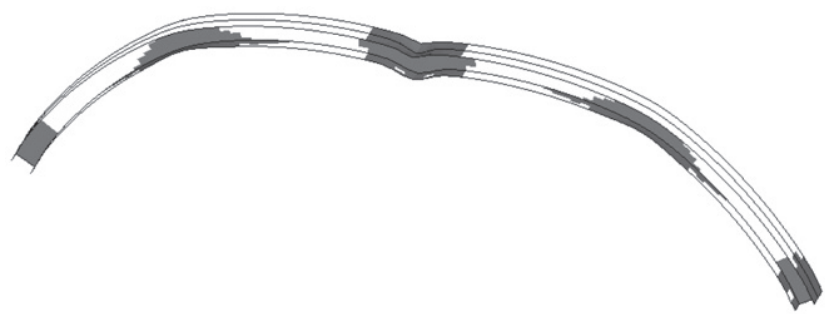

(a) Flexural mechanism for HE $300 \mathrm{~A}^{*}, S=12 \mathrm{~m}, 2 \gamma=120^{\circ}$

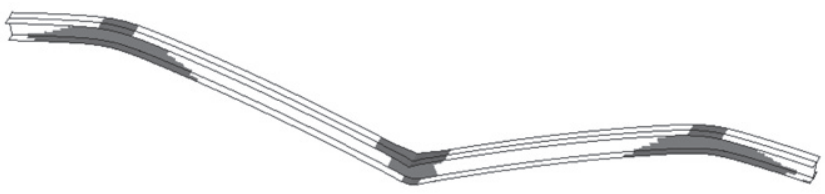

(b) Compressive mechanism for HE $300 \mathrm{~A}^{*}, S=12 \mathrm{~m}, 2 \gamma=20^{\circ}$

Fig. 18. Equivalent plastic strains at failure for a fixed arch (mesh not shown) for (a) flexural mechanism and (b) compressive mechanism.

For pin-supported arches with a uniformly distributed load the iterative method is able to give accurate values of the plastic collapse load. A remarkable error of 18 is observed for an arch with $2 \gamma=10$ and $S=16 \mathrm{~m}$.

\subsection{Fixed arch with central point load}

An identical loadcase compared to Section 5.2 is examined, with the exception that the arch is fixed instead of pin-supported. Three kinematic admissibility requirements have to be met in order to ascertain the correct mechanism occurs. All results are presented in Table 10. It can be seen that the kinematic admissibility requirements are not fulfilled for the shallow arches for which $2 \gamma \leqslant 30^{\circ}$. This explains the difference of $25-35 \%$ between the finite element results and results from the iterative method for $2 \gamma=10^{\circ}$.

\section{Design graphs}

A design graph to approximate the plastic collapse load of an arch was developed that is independent of the arch length $S$, full plastic moment $M_{\mathrm{pl}}$ and squash load $N_{\mathrm{pl}}$ of the cross section, thereby covering a wide range of arch configurations. A non-dimensional slenderness parameter $\lambda$ is introduced:

$\lambda=\frac{M_{\mathrm{pl}}}{N_{\mathrm{pl}} S}$

A similar parameter was proposed by Maeda and Fujimoto [11] and Chakrabarty [13]. The proposed graph yields plastic collapse loads in a non-dimensional form:

$w_{F}=\frac{F_{\mathrm{pl}} R}{M_{\mathrm{pl}}}$
$w_{\mathrm{Q}}=\frac{q_{\mathrm{pl}} R^{2}}{M_{\mathrm{pl}}}$

where $w_{\mathrm{F}}$ and $w_{\mathrm{Q}}$ are the normalized plastic collapse loads for an arch with a central point load and a uniformly distributed load, respectively. Design graphs have been developed for two different yield contours. The yield contour discussed in Section 2.3 in addition to a contour given in Eurocode 3 EN 1993-1-1 [20]. In Eurocode 3 the influence of axial force on the plastic moment capacity need

Table 8

Comparison of plastic collapse loads obtained from FEA and iterative method for pin-supported arches with central point load [kN].

\begin{tabular}{|c|c|c|c|c|c|c|c|c|c|c|}
\hline \multirow[t]{4}{*}{$2 \gamma\left({ }^{\circ}\right)$} & \multicolumn{5}{|c|}{$S=12 \mathrm{~m}$} & \multicolumn{5}{|c|}{$S=16 \mathrm{~m}$} \\
\hline & \multirow[t]{3}{*}{ FEA } & \multicolumn{3}{|c|}{ Iterative method } & \multirow[t]{3}{*}{ Ratio } & \multirow[t]{3}{*}{ FEA } & \multicolumn{3}{|c|}{ Iterative method } & \multirow[t]{3}{*}{ Ratio } \\
\hline & & & \multicolumn{2}{|c|}{ Kinematic admissibility } & & & & \multicolumn{2}{|c|}{ Kinematic admissibility } & \\
\hline & & & $\varphi_{2} / \varphi_{1}$ & $\Delta_{\mathrm{ver}} / \varphi_{1}$ & & & & $\varphi_{2} / \varphi_{1}$ & $\Delta_{\mathrm{ver}} / \varphi_{1}$ & \\
\hline 10 & 205 & 195 & $>0$ & $>0$ & 1.05 & 190 & 181 & $>0$ & $>0$ & 1.05 \\
\hline 30 & 400 & 398 & $>0$ & $>0$ & 1.01 & 354 & 343 & $>0$ & $>0$ & 1.03 \\
\hline 60 & 555 & 536 & $>0$ & $>0$ & 1.04 & 458 & 441 & $>0$ & $>0$ & 1.04 \\
\hline 90 & 603 & 603 & $>0$ & $>0$ & 1.00 & 499 & 483 & $>0$ & $>0$ & 1.03 \\
\hline 120 & 620 & 637 & $>0$ & $>0$ & 0.97 & 506 & 501 & $>0$ & $>0$ & 1.01 \\
\hline 150 & 644 & 649 & $>0$ & $>0$ & 0.99 & 492 & 498 & $>0$ & $>0$ & 0.99 \\
\hline 180 & 622 & 643 & $>0$ & $>0$ & 0.97 & 480 & 485 & $>0$ & $>0$ & 0.99 \\
\hline
\end{tabular}


Table 9

Comparison of plastic collapse loads obtained from FEA and iterative method for pin-supported arches with uniformly distributed load [kN/m].

\begin{tabular}{|c|c|c|c|c|c|c|c|c|c|c|}
\hline \multirow[t]{4}{*}{$2 \gamma\left({ }^{\circ}\right)$} & \multicolumn{5}{|c|}{$S=12 \mathrm{~m}$} & \multicolumn{5}{|c|}{$S=16 \mathrm{~m}$} \\
\hline & \multirow[t]{3}{*}{$\overline{\mathrm{FEA}}$} & \multicolumn{3}{|c|}{ Iterative method } & \multirow[t]{3}{*}{ Ratio } & \multirow[t]{3}{*}{$\overline{\mathrm{FEA}}$} & \multicolumn{3}{|c|}{ Iterative method } & \multirow[t]{3}{*}{ Ratic } \\
\hline & & & \multicolumn{2}{|c|}{ Kinematic admissibility } & & & & \multicolumn{2}{|c|}{ Kinematic admissibility } & \\
\hline & & & $\varphi_{2} / \varphi_{1}$ & $\Delta_{\text {ver }} / \varphi_{1}$ & & & & $\varphi_{2} / \varphi_{1}$ & $\Delta_{\mathrm{ver}} / \varphi_{1}$ & \\
\hline 10 & 36 & 36 & $>0$ & $>0$ & 1.00 & 27 & 23 & $>0$ & $>0$ & 1.18 \\
\hline 30 & 103 & 108 & $>0$ & $>0$ & 0.95 & 81 & 80 & $>0$ & $>0$ & 1.01 \\
\hline 60 & 200 & 199 & $>0$ & $>0$ & 1.01 & 144 & 144 & $>0$ & $>0$ & 1.00 \\
\hline 90 & 248 & 245 & $>0$ & $>0$ & 1.01 & 170 & 168 & $>0$ & $>0$ & 1.01 \\
\hline 120 & 251 & 248 & $>0$ & $>0$ & 1.01 & 164 & 161 & $>0$ & $>0$ & 1.02 \\
\hline 150 & 227 & 232 & $>0$ & $>0$ & 0.98 & 141 & 144 & $>0$ & $>0$ & 0.98 \\
\hline 180 & 204 & 211 & $>0$ & $>0$ & 0.97 & 123 & 127 & $>0$ & $>0$ & 0.97 \\
\hline
\end{tabular}

Table 10

Comparison of plastic collapse loads obtained from FEA and iterative method for fixed arches with central point load [kN].

\begin{tabular}{|c|c|c|c|c|c|c|c|c|c|c|c|c|}
\hline \multirow[t]{4}{*}{$2 \gamma\left({ }^{\circ}\right)$} & \multicolumn{6}{|c|}{$S=12 \mathrm{~m}$} & \multicolumn{6}{|c|}{$S=16 \mathrm{~m}$} \\
\hline & \multirow[t]{3}{*}{ FEA } & \multicolumn{4}{|c|}{ Iterative method } & \multirow[t]{3}{*}{ Ratio } & \multirow[t]{3}{*}{ FEA } & \multicolumn{4}{|c|}{ Iterative method } & \multirow[t]{3}{*}{ Ratic } \\
\hline & & & \multicolumn{3}{|c|}{ Kinematic admissibility } & & & & \multicolumn{3}{|c|}{ Kinematic admissibility } & \\
\hline & & & $\varphi_{2} / \varphi_{1}$ & $\Delta_{\text {ver }} / \varphi_{1}$ & $\varphi_{3} / \varphi_{1}$ & & & & $\varphi_{2} / \varphi_{1}$ & $\Delta_{\mathrm{ver}} / \varphi_{1}$ & $\varphi_{3} / \varphi_{1}$ & \\
\hline 10 & 240 & 178 & $<0$ & $>0$ & $<0$ & 1.35 & 210 & 168 & $>0$ & $>0$ & $<0$ & 1.25 \\
\hline 30 & 405 & 391 & $>0$ & $>0$ & $<\mathbf{0}$ & 1.04 & 362 & 345 & $>0$ & $>0$ & $<\mathbf{0}$ & 1.05 \\
\hline 60 & 579 & 557 & $>0$ & $>0$ & $>0$ & 1.04 & 474 & 467 & $>0$ & $>0$ & $>0$ & 1.01 \\
\hline 90 & 650 & 647 & $>0$ & $>0$ & $>0$ & 1.00 & 550 & 528 & $>0$ & $>0$ & $>0$ & 1.04 \\
\hline 120 & 687 & 701 & $>0$ & $>0$ & $>0$ & 0.98 & 570 & 562 & $>0$ & $>0$ & $>0$ & 1.01 \\
\hline 150 & 680 & 734 & $>0$ & $>0$ & $>0$ & 0.93 & 580 & 582 & $>0$ & $>0$ & $>0$ & 1.00 \\
\hline 180 & 700 & 753 & $>0$ & $>0$ & $>0$ & 0.93 & 582 & 581 & $>0$ & $>0$ & $>0$ & 1.00 \\
\hline
\end{tabular}

not be taken into account when the following requirements are satisfied.

$$
|N| \leqslant 0.25 N_{\mathrm{pl}} \quad \text { and } \quad|N| \leqslant 0.5 h_{0} t_{w} f_{y} / \gamma_{M 0}
$$

When these requirements are not met, the plastic moment capacity must be reduced according to the following yield contour $\psi$ :

$$
\begin{aligned}
\psi & =\left|\frac{M}{M_{\mathrm{pl}}}\right| \leqslant\left(1-\left|\frac{M}{M_{\mathrm{pl}}}\right|\right) /(1-0.5 a) \\
a & =\left(A-b t_{f}\right) / A
\end{aligned}
$$

where $h_{0}$ is the height of the web (or $h-2 t_{f}$ ), $A$ is the area of the cross-section, and $\gamma_{M 0}$ is a partial factor for cross-section resistance, recommended value: 1.0 .
All results for various values of $\lambda$ are presented in Figs. 19-21 for pin-supported arches subject to a central point load, pin-supported arches with a uniformly distributed load and for fixed arches subject to a central point load, respectively. They include two yield contours. The subtended angle $(2 \gamma)$ of the arches is varied between $10^{\circ}$ and $180^{\circ}$.

The kinematic admissibility imposes a limitation on the applicability of the iterative method for fixed arches. Especially for shallow configurations the kinematic admissibility requirement is no longer met and the obtained results cannot be used. The range of subtended angles for which the iterative method violates the kinematic admissibility requirements depends on the arch parameter $\lambda$. For fixed arches with relatively large values for $\lambda$, the threshold angle $2 \gamma$ beyond which the iterative method can be used is approximately $70^{\circ}$ (see Fig. 21). For arch configurations with smaller
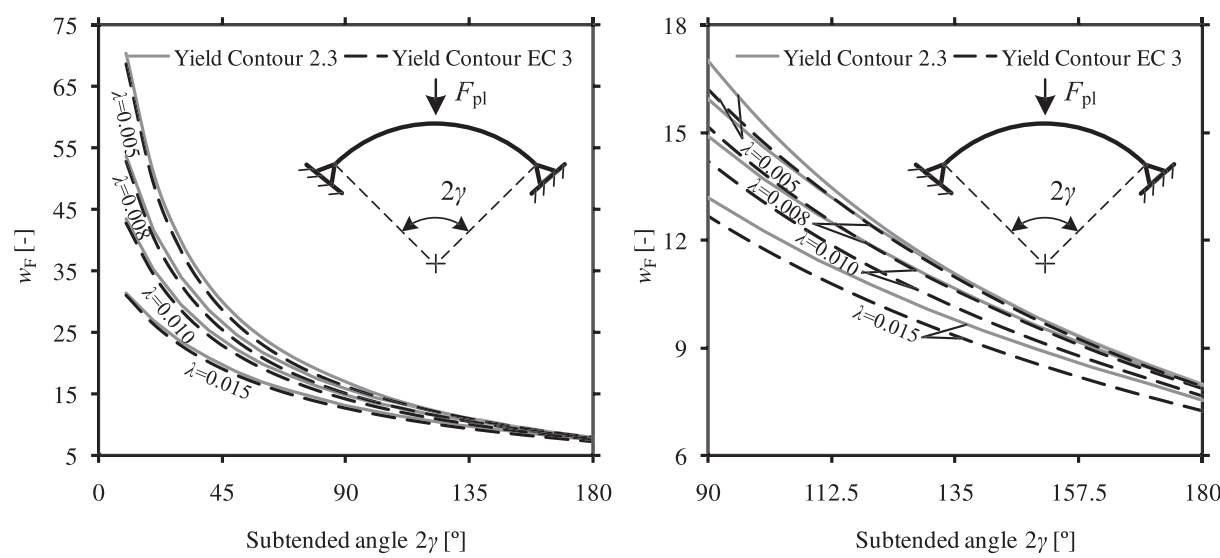

Fig. 19. Normalized collapse load $w_{F}$ for a pin-supported arch with central point load (enlarged scale to the right). 

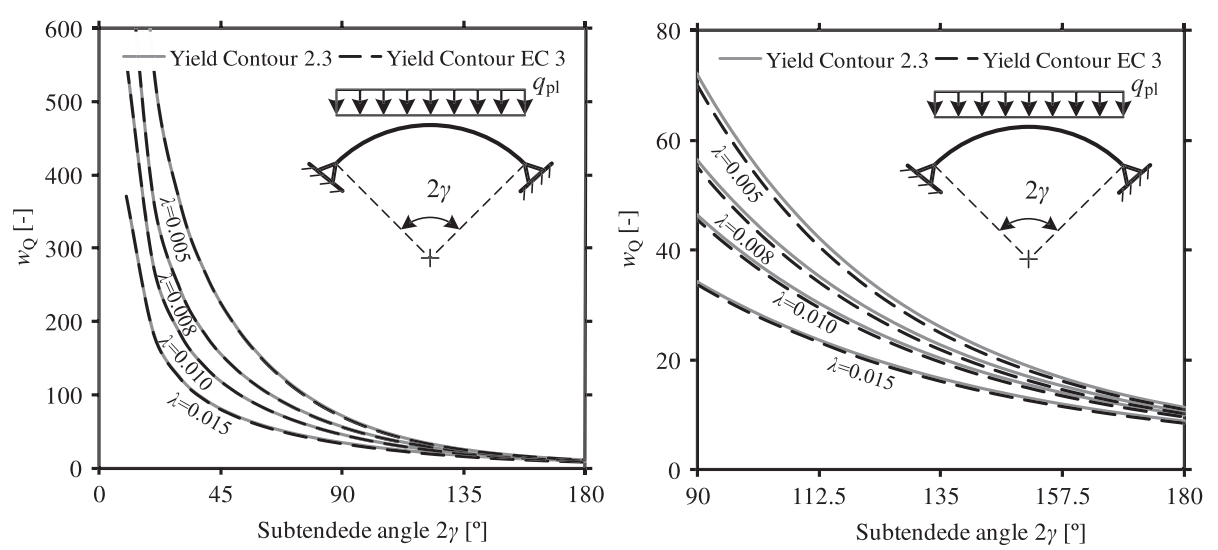

Fig. 20. Normalized collapse load $w_{Q}$ for a pin-supported arch with uniformly distributed load (enlarged area right).
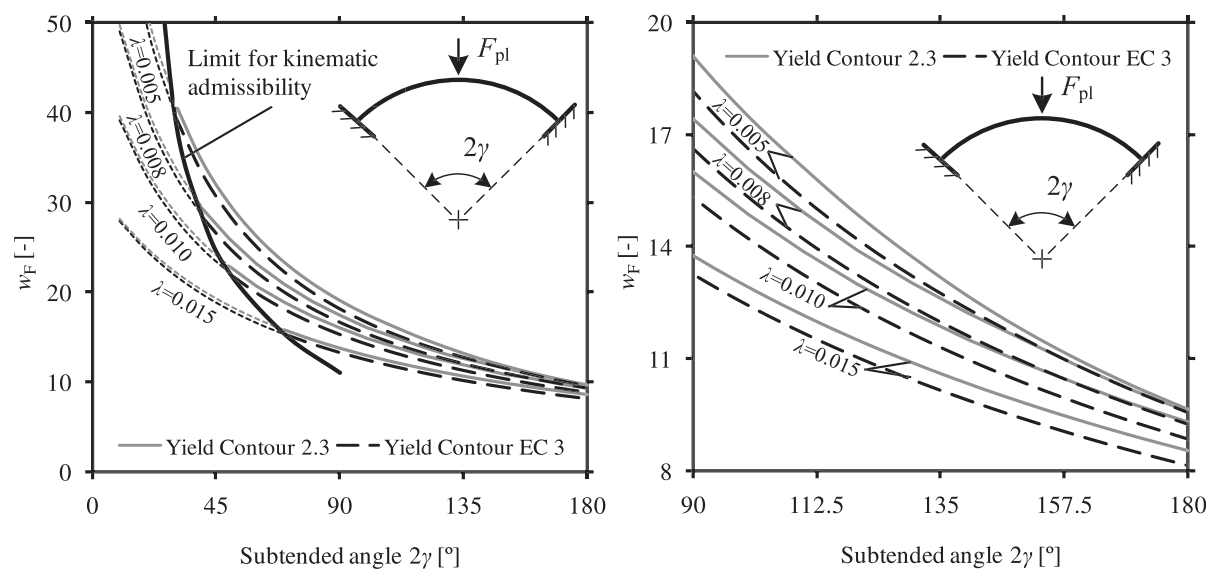

Fig. 21. The collapse load for a fixed arch with central point load (enlarged area right).

values for $\lambda$ this threshold angle $2 \gamma$ is $30^{\circ}$. In Fig. 21 the range of applicability of the iterative procedure is illustrated with a solid black line. The iterative procedure is allowed for arches with $\lambda$ values and subtended angles to the right of the black line.

In Figs. 19-21 it can be seen that the normalized collapse load increases, as the subtended angle decreases, for constant values of $\lambda$. In addition, as $\lambda$ increases, the normalized collapse load decreases for a constant value of $2 \gamma$. The influence of $\lambda$ on the normalized collapse load is closely related to the load case and support conditions. It can be seen that for a HE $300 \mathrm{~A}^{*}$ section the adoption of the yield contour from Section 2.3 or that of Eurocode 3 has little influence on the normalized collapse load. In general it can be stated that for the HE 300A* section the Eurocode 3 yield contour yields lower plastic collapse loads.

\section{Discussion}

\subsection{Change of mechanism}

The iterative method gives accurate values for the plastic collapse load of pin-supported arches with a central point load and pin-supported arches with a uniformly distributed load in addition to fixed arches with a central point load. From the comparison between the iterative method and finite element analyses it was found that for shallow fixed arches with a central point load the iterative method yields less accurate results. This lack of accuracy is attributed to the assumption of a flexural mechanism, not a compressive mechanism. The subtended angle $2 \gamma$ for which the flexural mechanism is no longer justified depends on the load case. For a

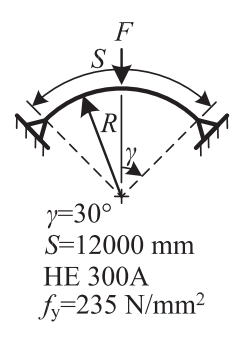

(a) arch configuration

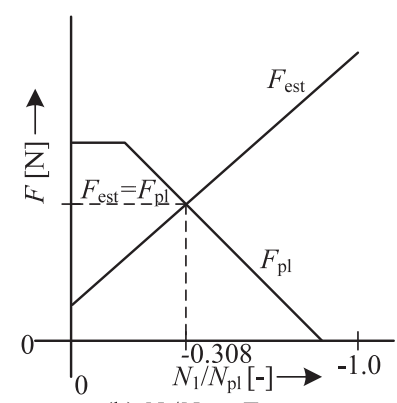

(b) $N_{1} / N_{\mathrm{pl}}-F$ curve

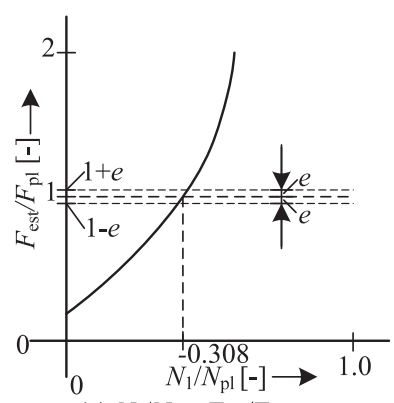

(c) $N_{1} / N_{\mathrm{pl}}-F_{\mathrm{est}} / F_{\mathrm{pl}}$ curve

Fig. 22. Graphical methods to obtain plastic collapse load. 
fixed arch subject to a central point load, the minimum angle $2 \gamma$ to initiate a flexural mechanism is approximately $30-70^{\circ}$ depending on the arch non-dimensional slenderness according to Eq. (41).

\subsection{Use of different yield contours}

The design graphs were developed for wide flange sections subject to bending about their major axes for which the yield contour is defined according to Eq. (1). The iterative method is also applicable to sections with a different yield contour. The yield contour can be expanded to include the influence of shear forces on the reduced plastic moment capacity. This alteration can be useful in the design of stocky arches for which the influence of shear forces is significant.

\subsection{Iterative method}

Although a closed-form solution is preferred over an iterative procedure, the latter was unavoidable, since there is a non-linear relationship between the acting loads and the reduced plastic moment capacity in the arch. For a pin-supported arch with a uniformly distributed load an additional iteration is necessary to find the compressive force at plastic hinge no. 2. An iterative method was also adopted in earlier studies: Onat and Prager [7] used a trial-and-error method to determine angle $\theta_{2}$ to compute the plastic collapse load and similarly Stevens [8] developed a socalled 'reiteration process' to adjust the horizontal thrust until both the lower and upper bound conditions were satisfied.

The iterative method can be replaced by graphical methods. This is schematically illustrated in Fig. 22 for a pin-supported arch with a central point load. When plotting a curve for $F_{\text {est }}$ (Eq. (6)) and a curve for $F_{\mathrm{pl}}$ (Eq. (10)) on the ordinate with the normalized normal force at the crown $N_{1} / N_{\mathrm{pl}}$ on the abscissa (Fig. 22b) the normal force at the onset of plastic collapse load is found at the intersection between both curves. It can be seen that when the normal force at the crown is $-0.308 N_{\mathrm{pl}}, F_{\mathrm{est}}$ is equal to $F_{\mathrm{pl}}$. An analogous representation is given in Fig. 22c with the ratio between $F_{\text {est }}$ and $F_{\mathrm{pl}}$ and the convergence criteria $e$ (as used in the iterative method) expressed versus the normalized normal force at the crown.

\section{Conclusions}

This paper presents an analytical method in the form of an iterative technique to estimate the in-plane plastic collapse load of circular pin-supported arches with a central point load, pin-supported arches with a uniformly distributed load and fixed arches with a central point load. The lower-bound theorem and upperbound-theorem of plastic theory were combined to arrive at an exact plastic collapse load. The influence of axial force on the plastic moment capacity of the cross-section is taken into account. Due to the non-linear relationship between the acting loads on the arch and the reduced plastic moment capacity in the plastic hinge it was found that an iterative technique is necessary to arrive at a plastic collapse load. The analyses were applied to wide flange sections. Finite element analyses with shell elements in the ANSYS v.11.0 environment were performed and revealed good coherence between numerical and analytical results. In order to 'convert' the iterative method into a practical tool, design graphs were developed. A slenderness parameter representing the arch length and two section properties were introduced to plot the normalized plastic collapse load in a design graph as a function of the subtended angle. The proposed iterative method can be easily expanded to include sections with different yield contours.

\section{Acknowledgements}

The procedure of the bisection method was implemented in the commercially available software program Mathematica ${ }^{\circledR}$ by Dr. M.C.M. Bakker and her valuable work is greatly acknowledged. The authors would like to express their gratitude for the contributions made to this project by P.L.C.A. Hanckmann MSc. and M.S. Dijk MSc.

\section{References}

[1] Pi Y-L, Trahair NS. In-plane buckling and design of steel arches. J Struct Eng ASCE 1999;125(110):1291-8.

[2] Pi Y-L, Bradford MA. In-plane strength and design of fixed steel I-section arches. Eng Struct 2004;26(3):291-301.

[3] Sakimoto T, Komatsu S. Ultimate strength formula for steel arches. J Struct Eng ASCE 1983;109:613-27.

[4] Pi Y-L, Trahair NS. Out-of-plane inelastic buckling and strength of steel arches. J Struct Eng ASCE 1998;124(2):174-83.

[5] Pi Y-L, Bradford MA. Out-of-plane strength design of fixed steel I-section arches. J Struct Eng ASCE 2005;131(4):560-8.

[6] Hendry AW. The plastic design of two-pinned mild steel arch ribs. Civil Eng Public Works Rev 1952;47:38-41.

[7] Onat ET, Prager W. Limit analysis of arches. J Mech Phys Solids 1953;1:77-89.

[8] Stevens LK. Carrying capacity of mild-steel arches. Proc Inst Civil Eng 1957;6:493-514.

[9] Cornforth RC, Childs SB. Computer analysis of two-hinged circular arches. J Struct Div 1967;93(2):319-38.

[10] Yamasaki T, Ishikawa N. Elasto-plastic analysis of circular arches. Trans Japan Soc Civ Eng 1968;158(10):1-16.

[11] Maeda Y, Fujimoto K. Study on calculation of plastic collapse load of twohinged arch. Trans Japan Soc Civ Eng 1970;174(2):25-40.

[12] Cohn MZ, Abdel-Rohman M. Analysis up to collapse of elasto-plastic arches. Comput Struct 1976;6:511-7.

[13] Chakrabarty J. Theory of plasticity. McGraw-Hill; 1988.

[14] Trahair NS, Pi Y-L, Clarke MJ, Papangelis JP. Plastic design of steel arches. Adv Struct Eng 1997;1(1):1-9.

[15] La Poutre DB, Snijder HH. In-plane stability of semicircular steel arches loaded in bending and compression. In: Proceedings of the annual SSRC annual stability conference; 2006. p. 163-82.

[16] La Poutre DB. In-plane stability of circular steel arches with variable subtended angles. In: Proceedings of the annual SSRC annual stability conference; 2007. p. 201-19.

[17] Ziemian RD. Guide to stability design criteria for metal structures. John Wiley \& Sons; 2010

[18] EN 1993 1-6. Eurocode 3. Design of steel structures. Part 1-6: Strength and stability of shell structures; 2005.

[19] Bakker MCM, Spoorenberg RC, Snijder HH, Hoenderkamp JCD. In-plane plastic limit load of steel circular arches, a lower bound limit analysis approach. In: Ofner R, Beg D, Fink J, Greiner R, Unterweger H editors, Proceedings of the 5th European conference on steel and composite structures (Eurosteel); 2008. p. 1831-6.

[20] EN 1993-1-1. Eurocode 3. Design of steel structures. General rules and rules for buildings. CEN European Committee for Standardization; 2004.

[21] Trahair NS, Bradford MA, Nethercot DA, Gardner L. The behaviour and design of steel structures to EC3. 4th ed. Taylor \& Francis Group; 2007. 